FEDERAL RESERVE BANK OF SAN FRANCISCO

WORKING PAPER SERIES

\title{
Sterilization, Monetary Policy, and Global Financial Integration
}

\author{
Joshua Aizenman \\ University of California, Santa Cruz \\ Reuven Glick \\ Federal Reserve Bank of San Francisco
}

July 2008

Working Paper 2008-15

http://www.frbsf.org/publications/economics/papers/2008/wp08-15bk.pdf

The views in this paper are solely the responsibility of the authors and should not be interpreted as reflecting the views of the Federal Reserve Bank of San Francisco or the Board of Governors of the Federal Reserve System. This paper was produced under the auspices of the Center for Pacific Basin Studies within the Economic Research Department of the Federal Reserve Bank of San Francisco. 
July 2008

\title{
Sterilization, Monetary Policy, and Global Financial Integration*
}

Joshua Aizenman

Department of Economics

University of California, Santa Cruz

jaizen@ucsc.edu

\author{
Reuven Glick \\ Economic Research Department \\ Federal Reserve Bank of San Francisco \\ reuven.glick@sf.frb.org
}

\begin{abstract}
:
This paper investigates the changing pattern and efficacy of sterilization within emerging market countries as they liberalize markets and integrate with the world economy. We estimate the marginal propensity to sterilize foreign asset accumulation associated with net balance of payments inflows, across countries and over time. We find that the extent of sterilization of foreign reserve inflows has risen in recent years to varying degrees in Asia as well as in Latin America, consistent with greater concerns about the potential inflationary impact of reserve inflows. We also find that sterilization depends on the composition of balance of payments inflows.
\end{abstract}

JEL Classification: F15, F21, F31

Keywords: foreign reserves, international reserves, sterilization, global financial integration

\footnotetext{
* We thank Michael Hutchinson, Menzie Chinn, an anonymous referee, and participants at the Review of International Economics - Santa Cruz Center for International Economics conference on "Global Liquidity," held at the University of California at Santa Cruz on April 11-12, 2008 for useful comments. We also thank Michael Simmons and Andrew Cohn for research assistance. The views expressed below do not represent those of the Federal Reserve Bank of San Francisco or the Board of Governors of the Federal Reserve System.
} 


\section{Introduction}

In the late 1980s and early 1990s, emerging market countries embraced growing financial liberalization and openness. However, by also trying to maintain some degree of both exchange rate stability and monetary independence, many of these countries experienced severe financial crises. In the aftermath of these crises, many emerging markets have adopted a policy configuration involving greater, though still managed, exchange rate flexibility, together with ongoing financial integration and some degree of domestic monetary independence. Hoarding of international reserves has become a key ingredient enhancing the stability of this new pattern. Concerns about the cost of maintaining monetary stability with this new policy mix suggest the need to support hoarding international reserves with more aggressive sterilization. Apprehensions about the opportunity costs of accumulating reserves and the fiscal and distortionary financial costs of sterilization, in turn, have raised questions about the long-run viability of this new policy mix, particularly the efficacy of sterilization.

In this paper we evaluate these considerations by estimating the marginal propensity to sterilize foreign asset accumulation over time for selected countries in Asia and Latin America. Our results confirm that the greater accumulation of foreign reserves in recent years has been associated with a greater intensity of sterilization by developing countries in Asia as well as in Latin America. In particular, we show that there has been a significant increase in the coefficient of sterilization in recent years. Thus the policies of hoarding international reserves and sterilizing the potential inflationary impact have complemented each other during recent years. In addition, we find that sterilization of foreign direct investment (FDI) inflows typically is less than that for current account surpluses and for non-FDI inflows, suggesting that misgivings about monetary instability depend on the composition of balance of payments inflows.

We also discuss the benefits and costs of sterilization. For many countries the costs of sterilization appear to be below the perceived benefits associated with monetary stability and reserve accumulation. However, we also present evidence suggesting that relative benefits to China and other countries have fallen in recent quarters. This implies limits to the sustainability of the new policy configuration in the near term.

Finally, we outline a model explaining how the ability to sterilize depends on imperfect substitutability of assets in a world where the costs of trading assets varies systematically across agents (due to possible scale effects) and across asset classes (due to varying liquidity and risk characteristics).

\section{The Trilemma}


A major lesson of the past decade or so has been the downside risk of combining international financial integration with soft exchange rate pegs. Each of the major international financial market-related crises since 1994 -- Mexico, in 1994, Thailand, Indonesia, and Korea in 1997, Russia and Brazil in 1998, and Argentina and Turkey in 2000 - has in some way involved a fixed or pegged exchange rate regime. At the same time, countries that did not have pegged rates_among them, Israel, Mexico, and South Africa in 1998-avoided crises of the type that afflicted emerging market countries with pegged rates. ${ }^{1}$ As a result, more emerging market countries have adopted a policy mix of managed exchange rates, while still trying to maintain some degree of domestic monetary control together with growing financial integration. They have accomplished this with a policy combination of massive reserve hoarding and sterilization.

A useful perspective for understanding the changing configuration of monetary policy by developing countries is provided by applying the framework of the impossible trinity dilemma the Trilemma. The Trilemma states that a country simultaneously may choose any two, but not all, of the following three goals: monetary independence, exchange rate stability and financial integration (see Obstfeld, Shambaugh, and Taylor, 2005 for further discussion and references dealing with the Trilemma).

Figure 1a illustrates the Trilemma problem. In terms of the triangle depicted in the figure, each of the three sides -- monetary independence, exchange rate stability, and financial integration -- has an attraction, but it is not possible to be simultaneously on all three sides of the triangle and thus attain all three goals. At the top vertex - labeled “closed capital markets” -- a country can have monetary policy control and a fixed exchange rate, but not financial integration. This was the preferred policy choice of most developing countries in the mid to late 1980s, as they maintained a combination of exchange rate stability and monetary independence, with relatively closed capital accounts.

As depicted in Figure 1b, in the late 1980s and early 1990s countries such as Mexico, Korea, and several other Asian economies, embraced growing financial liberalization and openness. However, as they opened more financially, they found that the goals of greater financial integration, exchange rate stability, and monetary independence were simultaneously unattainable. The inconsistent policy goals resulted in severe financial crises, in Mexico during

\footnotetext{
${ }^{1}$ This message has been communicated in well-known papers by Obstfeld and Rogoff (1995) and Fischer (2001). Related papers have raised the possibility that a pegged exchange rate can create a "trap" in an era of greater financial integration, whereby the regime initially confers gains in anti-inflation credibility, but ultimately results in an exit from the peg occasioned by a big enough adverse real shock that creates large welfare losses to the economy (see Eichengreen, 2001; Frankel, 1999; Edwards and Levy-Yeyati, 2005;
} Aizenman and Glick, 2008). 
1994-95 and in East Asia during 1997-98. ${ }^{2}$ These crises confirmed the tradeoffs associated with the Trilemma: a country opting for greater financial integration must give up exchange rate stability if it wishes to preserve a degree of monetary independence. Failure to do so induced crises, after which Mexico, Korea, and other countries opted for a new policy configuration associated with moving downwards within the Trilemma triangle. The emerging Trilemma configuration seems to involve greater financial integration and greater managed exchange rate flexibility, trading off exchange rate stability with capital mobility while maintaining some degree of monetary independence. ${ }^{3}$ In the early 1990s, Argentina adopted another Trilemma configuration corresponding to the vertex labeled "hard peg," involving exchange rate fixity, supported by a version of a currency board, and complete financial integration. Argentina also experienced a crisis in the early 2000s when ceding monetary policy independence became no longer viable.

Post crisis, more emerging markets have opted for a policy configuration involving more exchange rate flexibility, domestic monetary independence, and growing financial integration. But they are still engaging in a great degree of exchange rate management. So, in the face of pressures for their currencies to appreciate, they have been accumulating reserves and sterilizing. China vividly displays this policy mix, allowing greater de-facto financial integration, and in mid-2005 adopting managed exchange rate flexibility, while also accumulating and sterilizing massive amounts of foreign reserve inflows.

Econometric analysis suggests structural shifts in the pattern of reserve hoarding by developing countries (see Aizenman and Marion, 2003; Aizenman and Lee, 2008, and Cheung and Ito, 2007). One shift occurred in the early 1990s, as reflected in rising foreign reserve/GDP ratios, a trend that intensified shortly after the East Asian crisis of 1997-8, but subsided by 2000. A second structural shift seems to have taken place in the early 2000s, driven largely by the unprecedented increase in hoarding of foreign reserves by China.

This massive foreign reserve accumulation may be attributed to several factors. First, some countries have acquired reserves to satisfy precautionary demand needs. Reserves provide

\footnotetext{
${ }^{2}$ The list of countries with similar experiences is much longer (e.g., Russia, Brazil, and others). Our reference here to Mexico and East Asia is mostly due to the timing of their crises, each being the first in its respective region to experience a "sudden stop" episode, triggered by the sharp reversal of short-term financial flows ("hot money").

${ }^{3}$ Note that exchange rate stability may remain a desirable policy goal. A heavily managed float allows countries to stabilize their exchange rate, while retaining the option of exchange rate adjustment in the presence of large shocks without undergoing a balance of payment crisis. Similarly, countries may opt for a stable exchange rate, though at the cost of less monetary independence (see the experiences of Estonia, Hong Kong, and other countries). Hence, in line with the Trilemma, the trend towards greater financial integration by developing countries implies that countries must trade off the benefits of financial integration against the costs of reduced monetary autonomy and/or more flexible exchange rates.
} 
self insurance against sudden stops of foreign capital inflows, thereby offsetting the downside risk of greater financial integration. Secondly, reserves may be used to cushion the effects of terms of trade shocks on a country's real exchange rate and its exports, smoothing the adjustment of the current account. In addition, they allow countries to avoid relying on the IMF, World Bank, and other international financial organizations, etc. for implicit insurance. Lastly, reserve accumulation may occur as a byproduct of managing exchange rates to promote exports by undervaluing domestic currency. ${ }^{4}$

\section{Reserve Accumulation and Sterilization Response}

Reserve accumulation has monetary implications. When a central bank purchases foreign reserve assets, it must decide whether to fund it by increasing the reserve money base, which is potentially inflationary, or by reducing its net domestic assets, which sterilizes the impact on the domestic reserve money base. Central banks may offset the effects of reserve accumulation on the monetary base in a number of ways, including selling market instruments, such as government bonds or central bank bills or by using swaps or repurchase operations. With foreign exchange swaps, the central bank typically agrees to buy foreign exchange forward, while with repurchase operations ("repos”) the central bank sells securities with an agreement to buy them back in the future. When markets are thin, some authorities rely on non-market instruments, such as transferring the deposits of government and public financial institutions from the commercial banking system to the central bank or selling foreign exchange reserves to the government (perhaps to allow it to reduce external sovereign debt). ${ }^{5}$

\section{$\underline{\text { Some Plots }}$}

Figure 2 plots 4-quarter changes in central bank net foreign reserve assets $(F R)$ and in net domestic credit assets $(D C)$, each scaled by the reserve money stock $(R M)$ at the end of the period four quarters earlier, for selected Asian countries. ${ }^{6}$ Net foreign reserves are defined by taking the dollar-denominated level of foreign reserves and adjusting them for exchange rate

\footnotetext{
${ }^{4}$ For these reasons, even countries that maintained fixed exchange rates, such as China until mid-2005, opted to support their pegs by accumulating sizable amounts of foreign reserves.

${ }^{5}$ Monetary authorities also may seek to sterilize the effects of reserve inflows, not just on the reserve money base, but also on the broader money supply by, for example, increasing compulsory reserve requirements on bank deposits. China, for example, has raised reserve requirements significantly in recent years.

${ }^{6}$ Using four-quarter changes helps to smooth the data by eliminating much of the quarter to quarter noise.
} 
changes, to give a valuation-adjusted measure of changes in net foreign reserves in domestic currency. ${ }^{7}$ Net domestic credit assets $(D C)$ are defined as the reserve monetary base $(R M)$ minus net foreign reserves $(F R)$. Positive values of net foreign reserve accumulation by the central bank correspond to foreign reserve inflows. Negative values of net domestic credit correspond to reductions in domestic assets held by the monetary authorities.

In the case of China, the extent of sterilization was relatively limited until the early 2000s, as the monetary impact of reserve inflows (i.e. positive levels of $\Delta F R / R M$ ) was generally augmented by monetary stimulus from central bank acquisition of domestic assets (i.e. positive levels of $\triangle D C / R M .^{8}$ Since mid-2002, however, as China experienced sharply rising foreign reserve inflows, these inflows were accompanied by negative changes in domestic asset holdings by the central bank, primarily through sales of PBC bills, implying the reserve inflows were being sterilized. The increase in the extent of sterilization in the early 2000s implies a possible break from China’s prior sterilization behavior.

Other countries in Asia also have experienced significant reserve inflows in the aftermath of the Asia crisis. In the case, of Korea, for example, reserve inflows increased in 1999 and 2000, subsided somewhat, and then rose again in the period 2002-2005 around the time China began accumulating reserves at a rising rate. Korea’s monetary authorities responded to the monetary impact of these inflows by sterilization. A similar pattern of inflows and sterilization is apparent for other countries in Asia, particularly in Thailand, Malaysia, and India.

For comparison, we also show results for selected Latin American countries -- Argentina, Brazil, and Mexico. ${ }^{9}$ In the case of Argentina, modest reserve inflows emerged in 2003 in the aftermath of the country's financial crisis of 2001-02; however, these inflows were not evidently sterilized until the latter half of 2004 when changes in the domestic asset holdings of the central bank turned negative. In Brazil, reserve inflows began increasing in the latter half of 2004, accompanied by sterilization. A similar pattern of reserve inflows and offsetting declines in central bank domestic assets occurred in Mexico in 1996 in the aftermath of its 1994-95 peso crisis.

\footnotetext{
${ }^{7}$ Specifically, we define $\Delta F R_{t}=\left(S_{L C / \$}\right)_{t}\left(F R \$_{t}-F R \$_{t-1}\right)-\left(F L_{t}-F L_{t-1}\right)$, where $F R \$$ denotes foreign reserves in dollars (IMF line 1l.d), $S_{L C / \$}$ is the local currency price of the dollar, $F L$ denotes financial liabilities of the central bank (IMF line 16c), , and " $\Delta$ " is the change operator. Accordingly, we define $\Delta D C=\Delta R M-\triangle F R$.

${ }^{8}$ The exception is the period 1993 when China sterilized the effects of foreign reserve outflows by expanding the reserve money stock by increasing domestic asset holdings.

${ }^{9}$ The sample period for Argentina and Brazil begins 4 quarters after the implementation of their monetary reforms - 1992 Q1 for Argentina and 1995 Q2 for Brazil.
} 
We now turn to quantitatively estimating changes in the degree of sterilization. Our specification is very simple. We estimate the extent of sterilization by a simple regression of the monetary authorities' change in net domestic assets on the change in net foreign assets, where change is measured over four quarters, and scaled by the level of the reserve money stock four quarters ago. We also include the four-quarter growth rate of nominal GDP on the right-hand side to control for other explanatory variables, $Z$, that might influence the demand for money: ${ }^{10}$

$$
\Delta D C / R M_{-4}=\alpha+\beta \Delta F R / R M_{-4}+Z
$$

We estimate the sterilization coefficient, $\beta$, with OLS using 40 -quarter rolling samples. ${ }^{11}$ In these circumstances, a unitary coefficient, i.e. $\beta=-1$, on the variable $\Delta F R / R M$ represents full monetary sterilization of reserve changes, while $\beta=0$ implies no sterilization. A value of the sterilization coefficient between these levels, $-1<\beta<0$, indicates partial sterilization.

In our base specification $\mathrm{Z}$ is defined as the rate of nominal GDP growth. Presuming a stable demand for money, a rudimentary version of the monetary approach to the balance of payments implies that expansion of $D C$ by the central bank at the growth rate of GDP would meet the increase in the demand for money, without the need to hoard foreign reserves. Thus with full sterilization ( $\beta=-1$ ) the central bank allows domestic credit to accommodate fully higher demand for money due to GDP growth, but prevents any domestic credit expansion due to hoarding foreign reserves. A value of sterilization less than -1 may represent tighter monetary policy, potentially due to greater concerns about inflation. In this case hoarding a unit of foreign reserves reduces domestic assets held by the central bank by more than one unit, thereby reducing the monetary base. Similarly, a value of sterilization above zero may indicate expansionary monetary policy, potentially due to concerns about a credit crunch or exposure to a systemic crisis. $^{12}$

The results are plotted in Figure 3. Coefficient observations correspond to the calendar date of the $40^{\text {th }}$ quarter in each rolling sample. ${ }^{13}$

\footnotetext{
${ }^{10}$ We imputed quarterly GDP growth for some countries in our sample from a moving average of the prior year, current, and following year observations.

${ }^{11}$ We begin with the sample period 1984 Q2 to 1994 Q1, roll to 1984 Q3 - 1994 Q2, etc., ending with 1997 Q3 - 2007 Q2, depending on data availability.

${ }^{12}$ Note that the sterilization coefficient is only one parameter determining the stance of monetary policy. Fuller understanding of monetary policy requires information about changes in private and public banks' reserve requirements, discount window operations, etc.

${ }^{13}$ The figures report one standard error bands, using Newey-West errors adjusted for serial correlation of up to 3 quarters. Regression results for the full sample and tests of the null hypotheses that the sterilization coefficient differs from 0 or -1 are presented in tables below.
} 
In the case of China, observe that the sterilization coefficient began rising (in absolute value) from roughly 0.6 in 2000, a trend that accelerated in the latter half of 2002 and continued into 2006 when it peaked at almost 1.5, suggesting the presence of a break in behavior. ${ }^{14}$ The plot also indicates a reversal of China's sterilization behavior beginning in the fourth quarter of 2006. This evident decline in China’s degree of sterilization can be attributed to two possibilities. First, China’s foreign reserve accumulation in recent periods may be overstated to the extent that the reported figures have not been adjusted to take account of swaps and shifts of foreign reserve assets to China's nascent sovereign wealth fund. ${ }^{15}$ Second, China may indeed have reached limits to the extent of its ability to sterilize its massive reserve inflows.

In Korea a break in sterilization behavior is evident after the financial crisis of 1997-98, with the sterilization coefficient increasing from 0.9 to more than 1.0 by 1999 . Increases in sterilization, though to lesser extent, are observable in Thailand and Malaysia, while no change is evident in the case of Singapore. In the case of India, a modest increase in sterilization appears to have occurred in the mid 1990s after its financial crisis of 1991, followed by a further increase after 2002.

For comparison we also present rolling regression results for our three Latin America countries. As before, the sample ranges are limited to the period after the stabilization of monetary policy in 1991 in Argentina and 1994 in Brazil; in both cases some increases in sterilization in observable over the period. ${ }^{16}$ In the case of Mexico, sterilization increased modestly in 1996 and later around 2005.

In the Appendix Figures, we examine the sensitivity of our results to alternative regression specifications. Specifically, we plot rolling regression coefficients based on (i) nonoverlapping quarterly observations of 1 quarter changes, and (ii) nonoverlapping annual

\footnotetext{
${ }^{14}$ Central bank balance sheet data for China is available only from 1985 Q3, implying that the first 4quarter change observation begins in 1986 Q2, and the first 40-quarter rolling sample period is 1986 Q2 1996 Q1.

${ }^{15}$ China's sovereign wealth fund, the China Investment Corporation, was not formally established until the latter half of 2007 with an initial capitalization of $\$ 200$ billion out of China's total reserve holdings of more than $\$ 1.3$ trillion. But there are indications of central bank asset shifts to its predecessor institution, Huijins Investment, and to some Chinese commercial banks before then. Netting these amounts against reported foreign reserve holdings would reduce the magnitude of foreign reserve inflows and raise the implied level of central bank domestic assets, resulting in a lower estimated degree of sterilization.

${ }^{16}$ For Argentina, monetary policy was initially stabilized with the adoption of its currency board in 1991 Q1, implying that the first 4-quarter change observation begins in $1992 \mathrm{Q} 1$, and the first 40-quarter rolling sample period is 1992 Q1 - 2001 Q4. For Brazil, the first 40-quarter rolling sample is 1995 Q2 - 2005 Q1.
} 
observations of 4 quarter changes. ${ }^{17}$ Our general finding that sterilization has increased appears reasonably robust. ${ }^{18}$

Formal regressions assessing the significance of breaks in sterilization behavior are reported in Table 1. There we estimate equation (1) for the full sample period by also including a term interacting $\triangle F R / R M$ with a dummy variable DumBreak, defined with a value of unity for all periods beginning with each country's designated break date. We identified break dates for each country by the first observation after the 1997-98 Asia crisis (after the 1994-95 peso crisis in the case of Mexico) in which reserve inflows were positive and net domestic assets were reduced for at least two quarters in a row. ${ }^{19}$ A variant regression, reported in column (3), controls separately for sterilization behavior during a country's most recent period of significant foreign reserve outflows, denoted by DumCrisis. We report both Huber-White standard errors (in parentheses) and Newey-West standard errors (in square brackets). The Newey-West errors adjust for serial correlation of up to three quarters, a possible concern because of our use of overlapping quarterly observations of 4 quarter changes. ${ }^{20}$ The break date and crisis periods for each country are reported in Table 1. Our methodology identifies a break date of 2002 Q2 for China, 1998 Q4 for Korea, Thailand, Malaysia, and Singapore, and 2000 Q4 for India. The break dates for Argentina, Brazil, and Mexico are 2004 Q3, 2003 Q3, and 1996 Q4, respectively.

Observe that the coefficients on the net foreign reserve inflow variable and on the interactive term are always negative for all countries, implying the inflows were sterilized by reduction of central bank domestic assets and that this sterilization increased (i.e., the change in domestic asset holdings is more negative) after the break date. The coefficient on the interaction term is significant in the cases of China, Korea, and India, as well as in Argentina, Brazil, and Mexico. This supports the observation drawn from the rolling regression plots that sterilization behavior has intensified in recent years for emerging countries in Asia as well as in Latin

\footnotetext{
${ }^{17}$ In the first specification we also include a lagged dependent variable as well as 3 quarterly dummies as explanatory variables. See Mohanty and Turner (2006) who employ a similar specification; also see Glick and Hutchison (2003) who use an unconstrained vector error correction approach to estimate sterilization dynamics.

${ }^{18}$ The results for Malaysia using nonoverlapping 4-quarter changes are an apparent exception.

${ }^{19}$ We are aware of the potential biases inherent in using prior knowledge to pick break dates. For this reason we deliberately avoided choosing break dates based on the inflection points of our rolling regression plots. We do not feel that our general conclusions would be affected by use of more sophisticated time series approaches to identifying breaks.

${ }^{20}$ Recall that in our Appendix figures we plotted rolling regression coefficients based on samples of nonoverlapping quarterly and annual series observations. We do not use either of these samples in Table 1 as the quarterly series introduces excessive noise into the data while the annual series is insufficiently long. We prefer to use an overlapping sample of observations, while controlling for possible serial correlation through the use of appropriately adjusted standard errors.
} 
America. ${ }^{21}$ Also note that the coefficient on nominal GDP growth is positive, implying that the central bank supplies liquidity to the economy by increasing its claims in response to greater economic activity. $^{22}$

The rolling regressions suggest that sterilization increased in most countries in our sample after the Asia crisis or at the time that China began sterilizing significantly in 2002. To assess the extent to which countries are converging towards similar sterilization patterns, we make a cross-country comparison of sterilization behavior over time. Figure 4 reports the coefficient of variation of the sterilization coefficients for countries in Asia and Latin America as well as the two regions pooled together. We augment the sample of countries: in Asia, to our original sample of China, Korea, Thailand, Malaysia, Singapore, and India, we add Indonesia, Pakistan, and the Philippines; in Latin America, to our original sample of Argentina, Brazil, and Mexico, we add Chile, Colombia, and Peru. ${ }^{23}$ Observe that the coefficient of variation declined substantially in Asia over the period 2000 - 2005, after which it began to rise somewhat. ${ }^{24}$ In Latin America, the coefficient of variation fell, beginning in 2000. These results suggest the timing of the increase in the extent of sterilization across countries may have a common component.

\section{$\underline{\text { Sterilization and Inflation }}$}

Table 2 separates out the effects of inflation from real GDP changes on the central bank's management of its domestic asset holdings. It also examines the extent to which the response to inflation has changed over time and whether any changes in this response has affected the sterilization of foreign reserve inflows.

Columns (1) and (2) of Table 2 report the separate effects of inflation without and with real GDP as an explanatory variable. Observe that the coefficients on inflation and real GDP growth are generally positive and significant, consistent with the positive sign on nominal GDP

\footnotetext{
${ }^{21}$ It should be noted that we report significance results based on two-tailed tests of the null that sterilization behavior has changed. One-tailed tests of the null that sterilization behavior has increased (i.e., become more negative) would increase the significance of breaks.

${ }^{22}$ It should be noted that we do not take account of possible simultaneity bias because net foreign reserve changes may respond to domestic monetary policy, particularly when the central bank intervenes and affects the exchange rate. However, prior work seeking to control for the possible endogeneity of the explanatory variables in sterilization regressions through instrumental estimation has not found much effect on coefficient magnitudes and their standard errors as compared to OLS (e.g., Ouyang, Rajan, and Willett 2007).

${ }^{23}$ We only include Argentina and Brazil in the sample only ten years after the implementation of their monetary reforms, 2002 Q1 for Argentina and 2005 Q2 for Brazil.

${ }^{24}$ In addition to the decline in sterilization in recent quarters noted above in the case of China, sterilization in the Philippines has declined notably as well.
} 
observed earlier (the exceptions are the negative coefficients on real GDP for Korea and Thailand, though they are not significant). Note also that the magnitude of the coefficient of net foreign assets interacted with our break dummies are smaller (in absolute value) and in some cases less significant than those reported in Table 1. Column (3) augments the regression in column (2) by including an interaction variable involving the inflation rate with the break date dummies. For several countries - notably Korea, Thailand, Malaysia, Singapore, Argentina, and Brazil -- the coefficient on this variable is negative, suggesting an increase in anti-inflation monetary management by the central bank in recent years (though the coefficient is not significant for Korea and Singapore). Note also that we still find an increase in the sterilization response in most countries, as indicated by a negative coefficient on the interactive variable with foreign reserve inflows (the exceptions are Malaysia, Argentina, and Brazil). ${ }^{25}$ Thus, our result that developing countries have increased their degree of sterilization in recent years appears to be robust to allowing for any direct response to inflation pressures.

\section{Sterilization and the Composition of Balance of Payments Inflows}

Table 3 shows the evolution of current account balances, direct investment inflows, and other capital inflows, as well as reserve accumulation for emerging market countries as a whole, several regional groupings, and selected individual countries. The figures reported are annual averages of flows for subperiods before and after recent major financial crises, specifically the Mexican crisis of 1994-95 and the Asian and Russian crises of 1997-99.

Observe that the magnitude of reserve accumulation in Asia has steadily increased over time, consistent with our earlier observations based on central bank balance sheet data. ${ }^{26}$ Observe also that in the most recent period, 2000-2006, these inflows primarily have reflected current account surpluses, rather than large capital inflows. This is the opposite of the pattern seen in the late 1980s and 1990s, when most regions of the world experienced current account deficits and large capital inflows. Observe also that average direct foreign investment inflows have risen steadily for all emerging market regions over time. In contrast, average portfolio and other

\footnotetext{
${ }^{25}$ The increase in sterilization was significant for both Argentina and Brazil in Table 1, where we controlled for other determinants of domestic monetary policy with nominal GDP, but did not allow for any break in the response to this variable. Evidently, allowing a break in the response to inflation, as in column (3) in Table 3, soaks up the effect of a break in sterilization behavior. The result in Table 3 for Argentina is particularly problematic as the coefficient on the interactive term with reserve inflows is significant and positive; in this case the coefficient on the interactive inflation term is unusually large (in absolute value) as well as significant.

${ }^{26}$ Note that the figures reported here are changes expressed in dollar terms, as compared to changes in terms of local currency reported in earlier tables and charts.
} 
capital inflows ceased or declined dramatically after the Asia and Russian crises for almost all emerging markets. ${ }^{27}$

Does the sterilization response to reserve inflows vary according to the source of inflows, i.e., does the extent to which the central bank manage its domestic asset holdings depend on whether reserve inflows are associated with “cold” money flows” like FDI, or "hot” money inflows associated with other components of the balance of payments? Table 4 reports the results of estimating the sterilization response of the central bank to whether reserve inflows come from current account surpluses, foreign direct investment inflows, or non-FDI capital inflows. ${ }^{28}$ We also investigate whether these responses have varied at the same time as the break dates in sterilization behavior identified earlier. Consistent with our prior regression analysis, we measure variables in 4 quarter change terms, scaled by the lagged reserve money stock. ${ }^{29}$

As shown in column (2) of Table 4, the sterilization response to foreign direct investment is lower (in absolute magnitude, i.e. $\left|\beta_{1}\right|<\left|\beta_{0}\right|,\left|\beta_{1}\right|<\left|\beta_{2}\right|$ ) in several countries, including China, Korea, Thailand, Malaysia, and Singapore, as well as Brazil and Mexico (the latter in the case of the response relative to the current account). These differences are significant in China (relative to non-FDI inflows), Thailand (relative to the current account surplus), Malaysia, Singapore (relative to the current account), and Brazil. Column (3) of Table 4 interacts the individual balance of payments components with our break date dummies to detect whether there is more or less sensitivity to these components in recent years. Consistent with our findings in Table 3, we find greater sensitivity (i.e. more negative coefficient values) in the cases of China, Thailand, Malaysia (though not to the current account balance in Malaysia), and India (though not in response to FDI flows, where the response fell significantly).

Summarizing our empirical evidence on sterilization: The extent of sterilization of foreign reserve inflows has risen in recent years to varying degrees in Asia as well as in Latin America. This is consistent with greater concerns about the potential inflationary impact of reserve inflows. Sterilization depends on the composition of balance of payments inflows, i.e., for some countries the response to foreign direct investment inflows is less than that to the

\footnotetext{
${ }^{27}$ Hong Kong and Singapore had net portfolio outflows during 2000-06, offsetting the net capital inflows to other smaller East Asian countries, including Malaysia, the Philippines, Indonesia, and Thailand.

${ }^{28}$ If the central bank is insensitive to any concerns about the relative magnitudes of different components of the balance of payments one would expect that the relevant regression coefficients would be insignificant. The discussion about the risks of growing exposure to "hot money suggests that the central bank may indeed adjust its policies to reflect greater concern about "hot money" rather than about FDI flows.

${ }^{29}$ The quarterly data on dollar-denominated balance of payments flows are converted into local currency terms using the average local currency price of the dollar for each quarter.
} 
current account surplus or non-FDI inflows. This is consistent with the view that these countries are less concerned about the monetary impact of direct investment flows.

\section{Costs, Benefits, and Sustainability of Sterilization Policy}

Growing financial integration is an unavoidable outcome of deeper trade integration by developing countries. A byproduct of growing financial integration is greater exposure to financial instability. Concerns about financial and monetary instability have increased the complementarily between the extent of reserve hoarding and sterilization: The extent to which individual countries may continue to accumulate reserves and sterilize and the stability of this policy mix depends on the associated benefits and costs.

While providing useful services, international reserve management is subject to serious limitations. First, there are direct opportunity costs of reserves associated with the marginal productivity of public capital and/or the cost of external borrowing. Second, sterilization has fiscal costs associated with the difference between, on the one hand, the return paid on central bank liabilities issued to sterilize domestic liquidity (or the opportunity cost from foregone returns on domestic assets, such as government bonds, sold to the private sector) and, on the other hand, the return earned on foreign reserve assets.

Figure 5a plots a proxy for the fiscal costs of sterilization in the case of China, given by the difference between the 1-year People's Bank of China and U.S. Treasury bill rates (the spread is the vertical difference between the two plotted lines). ${ }^{30}$ Observe that the interest rate spread was positive, but shrinking in 2003 and 2004, and actually turned negative in 2005, implying China then was earning money on balance from its sterilization operations. The narrowing of this differential in recent quarters (it actually turned positive again in December 2007, however, implies that China’s sterilization costs have been rising. Figure 5b plots change in interest rate spreads for five Asian countries between June 2004 and May 2007, showing that sterilization costs increased in all these countries.

Sterilization and hoarding international reserves also involve macro and micro moral hazard costs. The macro moral hazard arises when reserve hoarding encourages opportunistic spending in regimes characterized by political instability and limited monitoring (see Aizenman and Marion (2004), who show that countries characterized by greater political instability and polarization opt to hold less international reserves). Micro moral hazard arises when reserve hoarding subsidizes risk taking. (Levy-Yeyati (2005) calls for liquid reserve requirement on

\footnotetext{
${ }^{30}$ Note that this proxy ignores the adverse valuation effects from continued appreciation of the yuan and other Asian currencies.
} 
banks, and an ex-ante suspension-of-convertibility clause.) Lastly, reserve accumulation and sterilization can encourage financial sector distortions. For example, greater use of non-market instruments (e.g. reserve requirements, direct credit controls) can hinder the development of corporate bond market and alter the behavior of banks. Also it may hinder financial development by segmenting the public debt market through the issuance of central bank liabilities instead of Treasury securities. $^{31}$

This discussion suggests that the extent to which a country may continue to sterilize depends also on the degree to which it is willing to tolerate financial repression and other distortions to its economy. In an Appendix we outline a model explaining how the ability to sterilize depends on imperfect substitutability of assets in a world where the costs of trading assets varies systematically across agents (due to possible scale effects) and across asset classes (due to varying liquidity and risk characteristics). Within this framework we show that policies fostering greater domestic financial repression also reduce the costs of sterilization. This suggests that countries able and willing to engage in greater financial sterilization will be able to sustain the policy configuration of reserve hoarding and sterilizing for a longer period of time. ${ }^{32}$

The stability of the current policy mix is further complicated by the extent to which each country's cost-benefit calculation depends on the actions of other countries. Countries following export-oriented growth strategies may choose to engage in competitive reserve accumulation to improve and maintain their competitiveness in exporting to industrial countries. Thus, for example, as long as China and its East Asian neighbors are trying to maintain competitiveness in exporting to the United States, - and limits to sterilization. Those countries with lower costs of sterilization, due for example to greater willingness to distort their financial systems, might end up hoarding increasingly large amounts of international reserves, winning the hoarding game at least in the short run. Arguably, this interpretation explains China's unprecedented increase in foreign reserves from 2002, now amounting to almost 50 percent of GDP and well above the levels of other East Asia countries (see Aizenman and Lee, 2008). Yet, this outcome may be fragile if it induces a country to accumulate to levels where the costs of sterilization exceed the benefit. These observations are consistent with the World Economic Outlook (2007), finding

\footnotetext{
${ }^{31}$ Sterilization operations of in this form also have costs. For example, reserve requirements act like a tax on banks which reduces financial intermediation and imposes a form of repression on the financial system.

${ }^{32}$ Our discussion points out that the costs of sterilization are the sum of direct opportunity costs and indirect costs associated with financial repression in the form of capital controls and higher reserve requirements imposed on the banking system. As the focus of our paper is on the positive aspects of recent sterilization trends, we do not attempt to estimate the overall costs of sterilization. Nevertheless, our discussion is consistent with the impact of changes in the direct opportunity costs of holding reserves on patterns of sterilization. Further investigation of these issues is left for future research.
} 
that resisting nominal exchange rate appreciation through sterilized intervention is likely to be ineffective when the influx of capital is persistent and large. Indeed, China's recently rising costs of sterilization may account for its recent decline in sterilization and increasing inflation rate. 


\section{References}

Aizenman, Joshua and Reuven Glick (2008). "Pegged Exchange Rate Regimes, A Trap?" Journal of Money, Credit, and Banking 40: 817-835.

Aizenman, Joshua and Jae-woo Lee (2008). "Financial versus Monetary Mercantilism - Longrun View of Large International Reserves Hoarding,” World Economy 3: 593-611.

Aizenman Joshua and Nancy Marion (2004). "International Reserves Holdings with Sovereign Risk and Costly Tax Collection,” Economic Journal 114: 569-591.

(2003). "The High Demand for International Reserves in the Far East: What's Going On?” Journal of the Japanese and International Economies 17: 370-400.

Cavoli, Tony and Ramkishen Rajan (2005). “The Capital Inflows Problem in Selected Asian Economies in the 1990s Revisited: The Role Of Monetary Sterilization,” National University Of Singapore, Singapore Centre for Applied and Policy Economics, December, 2005.

Edwards, Sebastian and Eduardo Levy-Yeyati (2005). "Flexible Exchange Rates as Shock Absorbers,” European Economic Review 49: 2079-2105.

Eichengreen, Barry (1999). "Kicking the Habit: Moving from Pegged Rates to Greater Exchange Rate Flexibility,” Economic Journal 109: 1-14.

Fischer, Stanley (2001). “Exchange Rate Regimes: Is the Bipolar View Correct?” The Journal of Economic Perspectives 15: 3-24.

Frankel, Jeffrey (1999). “No Single Currency Regime is Right for all Countries or at all Times,” NBER Working Paper 7338, September.

Giovannini, Alberto and Martha De-Melo (1993). “Government Revenue from Financial Repression,” American Economic Review 83: 953-963.

Glick, Reuven and Michael M. Hutchison (2000). "Foreign Reserve and Money Dynamics with Asset Portfolio Adjustment: International Evidence,” Journal of International Financial Markets, Institutions and Money 10: 229-247.

Levy-Yevati., Eduardo (2000). "Liquidity Insurance in a Financially Dollarized Economy,” NBER Working Paper 12345.

Mohanty, M.S. and Philip Turner (2006). "Foreign Exchange Reserve Accumulation in Emerging Markets: What are the Domestic Implications? BIS Quarterly Review, September.

Obstfeld, Maury and Kenneth Rogoff (1995). “The Mirage of Fixed Exchange Rates,” Journal of Economic Perspectives, 9: 73-96.

Obstfeld, Maury, Jay Shambaugh and Alan M. Taylor (2005). ”The Trilemma in History: Tradeoffs Among Exchange Rates, Monetary Policies, and Capital Mobility,“ Review of Economics and Statistics 3: 423-438. 
Ouyang, Alice, Ramkishen Rajan, and Thomas Willett (2007). "China as a Reserve Sink: The Evidence from Offset and Sterilization Coefficients,” Hong Kong Institute for Monetary Research Working Paper 2007-10, October.

World Economic Outlook (2007). "Managing Large Capital Inflows,” Chapter 3, International Monetary Fund, October. 
Table 1. Has Sterilization Increased in Magnitude Over Time? $\Delta D C / R M_{-4}=\alpha+\beta_{0} \Delta F R / R M_{-4}+\beta_{1}\left(\Delta F R / R M_{-4}\right)($ DumBreak $)+\beta_{2}(\Delta F R / R M)($ DumCrisis $\left.)+\beta_{3} \Delta \ln G N P\right)$

Panel A. Selected Asian Countries

\begin{tabular}{|c|c|c|c|c|c|c|c|c|c|}
\hline \multirow[b]{2}{*}{ Explanatory Variable } & \multicolumn{3}{|c|}{ China } & \multicolumn{3}{|c|}{ Korea } & \multicolumn{3}{|c|}{ Thailand } \\
\hline & (1) & $(2)$ & (3) & (1) & $(2)$ & (3) & (1) & $(2)$ & (3) \\
\hline \multirow[t]{3}{*}{$\Delta F R / R M$} & -0.782 & -0.768 & -0.827 & -0.770 & -0.833 & -0.744 & -0.931 & -1.039 & -0.929 \\
\hline & $(0.148)^{* * *}$ & $(0.096)^{* * *}$ & $(0.166)^{* * *}$ & $(0.039)^{* * *}$ & $(0.046)^{* * *}$ & $(0.038)^{* * *}$ & $(0.032)^{* * *}$ & $*(0.034)^{* * *}$ & $=(0.046)^{* * *}$ \\
\hline & {$[0.232]^{* * *}$} & {$[0.138]^{* * *}$} & {$[0.253]^{* * *}$} & {$[0.049]^{* * *}$} & {$[0.063]^{* * *}$} & {$[0.041]^{* * *}$} & {$[0.043]^{* * *}$} & $*[0.037]^{* * *}$ & {$[0.054]^{* * *}$} \\
\hline \multirow[t]{3}{*}{$(\Delta F R / R M)($ DumBreak $)$} & -0.345 & -0.301 & -0.256 & -0.252 & -0.132 & -0.193 & -0.099 & -0.034 & -0.044 \\
\hline & $(0.132)^{* *}$ & $(0.102)^{* * *}$ & $(0.146)^{*}$ & $(0.042)^{* * *}$ & $=(0.057)^{* *}$ & $(0.047)^{* * *}$ & $(0.032)^{* * *}$ & $*(0.044)$ & $(0.043)$ \\
\hline & {$[0.199]^{*}$} & {$[0.151]^{* *}$} & -0.226 & {$[0.056]^{* * *}$} & {$[0.074]^{*}$} & {$[0.048]^{* * *}$} & {$[0.044]^{* *}$} & {$[0.054]$} & {$[0.061]$} \\
\hline \multirow[t]{3}{*}{$(\Delta F R / R M)($ DumCrisis $)$} & & & 0.176 & & & -0.219 & & & -0.127 \\
\hline & & & $(0.304)$ & & & $(0.064)^{* * *}$ & & & $(0.053)^{* *}$ \\
\hline & & & {$[0.395]$} & & & {$[0.058]^{* * *}$} & & & {$[0.059]^{* *}$} \\
\hline \multirow[t]{3}{*}{$\Delta \ln (G N P)$} & & 0.889 & 0.918 & & 1.058 & 1.198 & & 1.200 & 0.820 \\
\hline & & $(0.088)^{* * *}$ & $=(0.103)^{* * *}$ & & $(0.324)^{* * *}$ & $(0.326)^{* * *}$ & & $(0.262)^{* * *}$ & $(0.282)^{* * *}$ \\
\hline & & {$[0.143]^{* * *}$} & $=[0.162]^{* * *}$ & & {$[0.368]^{* * *}$} & {$[0.400]^{* * *}$} & & {$[0.259]^{* * *}$} & {$[0.320]^{* *}$} \\
\hline$H_{0}: \beta_{0}=-1$ & 2.183 & $5.837 * *$ & 1.083 & $34.299 * * *$ & $13.181^{* * *}$ & $44.776^{* * *}$ & $4.639 * *$ & 1.319 & 2.431 \\
\hline$H_{0}: \beta_{0}+\beta_{1}=-1$ & 2.194 & 1.046 & 1.223 & 0.55 & 1.226 & 3.892 & 0.839 & 0.024 & 0.659 \\
\hline Adjusted R-squared & 0.674 & 0.837 & 0.835 & 0.952 & 0.957 & 0.96 & 0.971 & 0.978 & 0.979 \\
\hline Break date & & 2002 Q2 & & & 1998 Q4 & & & 1998 Q4 & \\
\hline Crisis period & & 92 Q3 - 199? & 3 Q3 & & 97 Q1 - 1998 & 8 Q3 & & 1997 Q1-98 & Q3 \\
\hline Sample period & & 86 Q2 - 200? & 7 Q2 & & 85 Q1- 2007 & 7 Q2 & & 985 Q1-2007 & 7 Q2 \\
\hline Observations & & 85 & & & 90 & & & 90 & \\
\hline
\end{tabular}

Panel B. Other Selected Asian Countries

\begin{tabular}{|c|c|c|c|c|c|c|c|c|c|}
\hline \multirow[b]{2}{*}{ Explanatory Variable } & \multicolumn{3}{|c|}{ Malaysia } & \multicolumn{3}{|c|}{ Singapore } & \multicolumn{3}{|c|}{ India } \\
\hline & $(2)$ & (3) & (3) & (1) & $(2)$ & (3) & (1) & $(2)$ & (3) \\
\hline \multirow[t]{3}{*}{$\Delta F R / R M$} & -0.858 & -0.880 & -0.874 & -0.935 & -0.984 & -0.993 & -0.822 & -0.805 & -0.770 \\
\hline & $(0.140)^{* * *}$ & $(0.137)^{* * *}$ & $(0.152)^{* * *}$ & $(0.018)^{* * *}$ & $(0.019)^{* * *}$ & $(0.024)^{* * *}$ & $(0.108)^{* * *}$ & $(0.090)^{* * *}$ & $(0.099)^{* * *}$ \\
\hline & {$[0.205]^{* * *}$} & {$[0.200]^{* * *}$} & {$[0.221]^{* * *}$} & {$[0.021]^{* * *}$} & {$[0.018]^{* * *}$} & {$[0.024]^{* * *}$} & {$[0.161]^{* * *}$} & {$[0.115]^{* * *}$} & {$[0.122]^{* * *}$} \\
\hline \multirow{3}{*}{$(\triangle F R / R M)($ DumBreak $)$} & -0.193 & -0.191 & -0.196 & -0.044 & -0.018 & -0.014 & -0.208 & -0.144 & -0.169 \\
\hline & $(0.141)$ & $(0.142)$ & $(0.153)$ & $(0.011)^{* * *}$ & $=(0.011)$ & $(0.013)$ & $(0.108)^{*}$ & $(0.087)^{*}$ & $(0.092)^{*}$ \\
\hline & {$[0.21]$} & {$[0.211]$} & {$[0.227]$} & {$[0.015]^{* * *}$} & $=[0.015]$ & {$[0.016]$} & [0.165] & {$[0.114]$} & {$[0.116]$} \\
\hline \multirow[t]{3}{*}{$(\Delta F R / R M)($ DumCrisis $)$} & & & -0.077 & & & 0.052 & & & -0.363 \\
\hline & & & $(0.299)$ & & & $(0.083)$ & & & $(0.181)^{* *}$ \\
\hline & & & {$[0.326]$} & & & {$[0.054]$} & & & {$[0.215]^{*}$} \\
\hline \multirow[t]{3}{*}{$\Delta \ln (G N P)$} & & 1.732 & 1.748 & & 0.567 & 0.584 & & 0.924 & 0.919 \\
\hline & & $(0.416)^{* * *}$ & $(0.442)^{* * *}$ & & $(0.120)^{* * *}$ & $(0.129)^{* * *}$ & & $(0.152)^{* * *}$ & $(0.147)^{* * *}$ \\
\hline & & {$[0.665]^{* *}$} & {$[0.708]^{* *}$} & & {$[0.167]^{* * *}$} & {$[0.173]^{* * *}$} & & {$[0.221]^{* * *}$} & {$[0.210]^{* * *}$} \\
\hline$H_{0}: \beta_{0}=-1$ & 1.036 & 0.761 & 0.689 & $12.596 * * *$ & 0.767 & 0.083 & 2.722 & $4.744^{* *}$ & $5.386^{* * *}$ \\
\hline$H_{0}: \beta_{0}+\beta_{1}=-1$ & $3.791^{*}$ & $8.940 * * *$ & $9.081 * * *$ & 1.888 & 0.006 & 0.182 & 0.837 & $2.606^{*}$ & $3.231^{*}$ \\
\hline Adjusted R-squared & 0.829 & 0.851 & 0.849 & 0.983 & 0.986 & 0.986 & 0.849 & 0.892 & 0.893 \\
\hline Break date & \multicolumn{3}{|c|}{1998 Q4 } & \multicolumn{3}{|c|}{1998 Q4 } & \multicolumn{3}{|c|}{2000 Q4 } \\
\hline Crisis period & \multicolumn{3}{|c|}{1997 Q3 - 1998 Q3 } & \multicolumn{3}{|c|}{1997 Q4 -1998 Q3 } & \multicolumn{3}{|c|}{1990 Q4 - 1991 Q4 } \\
\hline Sample period & \multirow{2}{*}{\multicolumn{3}{|c|}{$\begin{array}{c}1985 \text { Q1 -2007 Q2 } \\
90\end{array}$}} & \multirow{2}{*}{\multicolumn{3}{|c|}{$\begin{array}{c}1985 \text { Q1- } 2007 \text { Q2 } \\
90\end{array}$}} & \multirow{2}{*}{\multicolumn{3}{|c|}{$\begin{array}{c}1985 \text { Q1- } 2006 \text { Q4 } \\
88\end{array}$}} \\
\hline Observations & & & & & & & & & \\
\hline
\end{tabular}


Table 1. Has Sterilization Increased in Magnitude Over Time? (cont’d)

\begin{tabular}{|c|c|c|c|c|c|c|c|c|c|}
\hline \multirow[b]{3}{*}{ Explanatory Variable } & \multicolumn{6}{|c|}{ Panel C. Selected Latin American Countries } & \multirow{2}{*}{\multicolumn{3}{|c|}{ Mexico }} \\
\hline & \multicolumn{3}{|c|}{ Argentina } & \multicolumn{3}{|c|}{ Brazil } & & & \\
\hline & (1) & (2) & (3) & (1) & $(2)$ & (3) & $(1)$ & $(2)$ & (3) \\
\hline \multirow[t]{3}{*}{$\Delta F R / R M$} & -0.989 & -1.006 & -0.783 & -0.861 & -0.938 & -0.569 & -0.959 & -0.975 & -0.934 \\
\hline & $(0.033)^{* * *}$ & $(0.030)^{* * *}$ & $(0.089)^{* * *}$ & $(0.136)^{* * *}$ & $(0.135)^{* * *}$ & $(0.186)^{* * *}$ & $(0.027)^{* * *}$ & $(0.018)^{* * *}$ & $(0.036)^{* * *}$ \\
\hline & {$[0.034]^{* * *}$} & {$[0.020]^{* * *}$} & {$[0.092]^{* * *}$} & {$[0.183]^{* * *}$} & {$[0.188]^{* * *}$} & {$[0.237]^{* *}$} & {$[0.034]^{* * *}$} & {$[0.022]^{* * *}$} & {$[0.044]^{* * *}$} \\
\hline \multirow[t]{3}{*}{$(\Delta F R / R M)($ DumBreak $)$} & -0.019 & -0.257 & -0.282 & -0.419 & -0.284 & -0.539 & -0.233 & -0.077 & -0.103 \\
\hline & $(0.102)$ & $(0.123)^{* *}$ & $(0.107)^{* *}$ & $(0.183)^{* *}$ & $(0.180)$ & $(0.217)^{* *}$ & $(0.056)^{* * *}$ & $(0.038)^{* *}$ & $(0.043)^{* *}$ \\
\hline & {$[0.168]$} & {$[0.174]$} & {$[0.165]^{*}$} & {$[0.219]^{*}$} & {$[0.246]$} & {$[0.290]^{*}$} & {$[0.092]^{* *}$} & {$[0.051]$} & {$[0.057]^{*}$} \\
\hline \multirow[t]{3}{*}{$(\Delta F R / R M)($ DumCrisis $)$} & & & -0.262 & & & -0.828 & & & -0.071 \\
\hline & & & $(0.102)^{* *}$ & & & $(0.246)^{* * *}$ & & & $(0.040)^{*}$ \\
\hline & & & {$[0.105]^{* *}$} & & & {$[0.295]^{* * *}$} & & & {$[0.050]$} \\
\hline \multirow[t]{3}{*}{$\Delta \ln (G N P)$} & & 1.272 & 0.936 & & 0.138 & 0.131 & & 0.394 & 0.399 \\
\hline & & $(0.352)^{* * *}$ & $(0.310)^{* * *}$ & & $(0.021)^{* * *}$ & $(0.025) * * *$ & & $(0.057)^{* * *}$ & $(0.061)^{* * *}$ \\
\hline & & {$[0.412]^{* * *}$} & {$[0.335]^{* * *}$} & & {$[0.025]^{* * *}$} & {$[0.027]^{* * *}$} & & {$[0.075]^{* * *}$} & {$[0.078]^{* * *}$} \\
\hline$H_{0}: \beta_{0}=-1$ & 0.103 & 0.047 & $5.756^{* *}$ & 1.045 & 0.213 & $5.402 * *$ & 2.36 & 1.826 & $3.45^{*}$ \\
\hline$H_{0}: \beta_{0}+\beta_{1}=-1$ & 0.175 & $5.820 * *$ & 0.653 & $4.957^{* *}$ & 3.386 & 0.956 & $17.411^{* * *}$ & 2.518 & 1.097 \\
\hline Adjusted R-squared & 0.949 & 0.968 & 0.972 & 0.591 & 0.64 & 0.683 & 0.958 & 0.979 & 0.98 \\
\hline Break date & & 2004 Q3 & & & 2003 Q3 & & & 1996 Q4 & \\
\hline Crisis period & 200 & $0 \mathrm{Q} 4-2003$ & 3 Q1 & & 98 Q3 -1995 & 9 Q4 & & 94 Q2 - 199 & 5 Q4 \\
\hline Sample period & & 92 Q1 -2007 & Q2 & & 95 Q2 - 200 & 7 Q2 & & 85 Q1- 2007 & 7 Q2 \\
\hline Observations & & 62 & & & 49 & & & 90 & \\
\hline
\end{tabular}

Note: The table reports coefficients of regressing central bank net domestic credit on net foreign reserves, measured as 4quarter changes, scaled by the lagged reserve money stock $(R M) . \Delta \ln (G N P)$ is the 4 quarter percent change in nominal GDP, DumBreak is a dummy variable denoting break point in sterilization behavior, and DumCrisis is a dummy variable denoting the most recent period of significant reserve outflows. Huber-White standard errors in parentheses; Newey-West standard errors adjusted for serial correlation up to three quarters in square brackets. F statistic for null hypothesis tests. Significance at $1 \%, 5 \%, 10 \%$ indicated by $* * *, * *$, and $*$, respectively. Constant not reported. 
Table 2. Does Sterilization Depend on Inflation?

$\Delta D C / R M_{-4}=\alpha+\beta_{0} \Delta F R / R M_{-4}+\beta_{1}\left(\Delta F R / R M_{-4}\right)($ DumBreak $)+\beta_{2} \Delta \ln (I N F L)+\beta_{3} \Delta \ln (I N F L)($ DumBreak $)+\beta_{4} \Delta \ln (R G N P)$

Panel A. Selected Asian Countries

\begin{tabular}{|c|c|c|c|c|c|c|c|c|c|}
\hline \multirow[b]{2}{*}{ Explanatory Variable } & \multicolumn{3}{|c|}{ China } & \multicolumn{3}{|c|}{ Korea } & \multicolumn{3}{|c|}{ Thailand } \\
\hline & $(1)$ & $(2)$ & (3) & (1) & (2) & (3) & (1) & (2) & (3) \\
\hline \multirow[t]{3}{*}{$\Delta F R / R M$} & -0.786 & -0.778 & -0.778 & -0.767 & -0.758 & -0.760 & -0.925 & -0.930 & -0.936 \\
\hline & \multirow{2}{*}{\multicolumn{3}{|c|}{$\begin{array}{l}(0.130)^{* * *}(0.122)^{* * *}(0.123)^{* * *} \\
{[0.114]^{* * *}[0.116]^{* * *}[0.117]^{* * *}}\end{array}$}} & \multicolumn{3}{|c|}{$(0.035)^{* * *}(0.038)^{* * *}(0.039)^{* * *}$} & \multirow{2}{*}{\multicolumn{3}{|c|}{$\begin{array}{l}(0.031)^{* * *}(0.030)^{* * *}(0.029)^{* * *} \\
{[0.019]^{* * *}[0.019]^{* * *}[0.019]^{* * *}}\end{array}$}} \\
\hline & & & & {$[[0.038] * *$} & $*[0.039]^{* *}$ & $*[0.040]^{* * *}$ & & & \\
\hline \multirow[t]{3}{*}{$(\Delta F R / R M)($ DumBreak $)$} & -0.176 & -0.191 & -0.214 & -0.216 & -0.223 & -0.215 & -0.069 & -0.066 & -0.030 \\
\hline & $(0.126)$ & $(0.117)$ & $(0.123)^{*}$ & $(0.045)^{* *}$ & $*(0.046) * *$ & $*(0.052) * * *$ & $(0.042)$ & $(0.042)$ & $(0.044)$ \\
\hline & {$[0.115]$} & [0.119] & {$[0.143]$} & {$[0.045]^{* *}$} & $*[0.046]^{* *}$ & $*[0.053]^{* * *}$ & {$[0.038]^{*}$} & {$[0.038]^{*}$} & {$[0.038]$} \\
\hline \multirow[t]{3}{*}{$\Delta \ln (I N F L)$} & 0.816 & 0.795 & 0.791 & 1.79 & 1.631 & 1.644 & 1.051 & 1.145 & 1.176 \\
\hline & \multirow{2}{*}{\multicolumn{3}{|c|}{$\begin{array}{l}(0.117)^{* * *}(0.108)^{* * *}(0.109)^{* * *} \\
{[0.107]^{* * *}[0.116]^{* * *}[0.118]^{* * *}}\end{array}$}} & $(0.705)^{* *}$ & $(0.717)^{* *}$ & $(0.711)^{* *}$ & $(0.644)$ & $(0.684)^{*}$ & $(0.719)$ \\
\hline & & & & {$[0.678]^{* *}$} & $*[0.678]^{* *}$ & $*[0.703]^{* *}$ & {$[0.454]^{* *}$} & {$[0.465]^{* *}$} & {$[0.446]^{* * *}$} \\
\hline \multirow[t]{3}{*}{$\Delta \ln (I N F L)($ DumBreak $)$} & \multirow{3}{*}{\multicolumn{3}{|c|}{$\begin{array}{l}0.350 \\
(0.597) \\
{[1.150]}\end{array}$}} & & & -0.324 & & & -1.687 \\
\hline & & & & & & $(1.057)$ & & & $(0.604)^{* * *}$ \\
\hline & & & & & & {$[1.116]$} & & & {$[0.577]^{* * *}$} \\
\hline \multirow[t]{3}{*}{$\Delta \ln (R G N P)$} & & 0.180 & 0.181 & & -0.813 & -0.741 & & -0.385 & -0.240 \\
\hline & & $(0.453)$ & $(0.455)$ & & $(0.685)$ & $(0.711)$ & & $(0.38)$ & $(0.389)$ \\
\hline & & [0.383] & {$[0.385]$} & & {$[0.837]$} & {$[0.878]$} & & {$[0.403]$} & [0.389] \\
\hline$H_{0}: \beta_{0}=-1$ & $2.710 *$ & $3.314^{*}$ & $3.274 *$ & $45.496 * * *$ & k $39.8 * * *$ & $38.146^{* * *}$ & $5.946^{* *}$ & $5.345 * *$ & $4.712^{* *}$ \\
\hline$H_{0}: \beta_{0}+\beta_{1}=-1$ & 0.264 & 0.188 & 0.009 & 0.241 & 0.295 & 0.433 & 0.019 & 0.011 & 0.898 \\
\hline Adjusted R-squared & 0.804 & 0.802 & 0.799 & 0.955 & 0.955 & 0.954 & 0.972 & 0.972 & 0.975 \\
\hline Break date & \multicolumn{3}{|c|}{2002 Q2 } & \multicolumn{3}{|c|}{1998 Q4 } & \multirow{2}{*}{\multicolumn{3}{|c|}{$\begin{array}{c}1998 \text { Q4 } \\
1985 \text { Q1 - 2007O2 }\end{array}$}} \\
\hline Sample period & \multirow{2}{*}{\multicolumn{3}{|c|}{1987 Q1 - 2007 Q2 }} & \multirow{2}{*}{\multicolumn{3}{|c|}{1985 Q1 - 2007Q2 }} & & & \\
\hline Observations & & & & & & & \multicolumn{3}{|c|}{$\begin{array}{c}1985 \text { Q1 - 2007Q2 } \\
90\end{array}$} \\
\hline
\end{tabular}

Panel B. Other Selected Asian Countries

\begin{tabular}{|c|c|c|c|c|c|c|c|c|c|}
\hline \multirow[b]{2}{*}{ Explanatory Variable } & \multicolumn{3}{|c|}{ Malaysia } & \multicolumn{3}{|c|}{ Singapore } & \multicolumn{3}{|c|}{ India } \\
\hline & (1) & (2) & (3) & (1) & (2) & (3) & (1) & (2) & (3) \\
\hline \multirow[t]{3}{*}{$\Delta F R / R M$} & -0.861 & -0.930 & -0.961 & -0.959 & -0.977 & -0.978 & -0.816 & -0.751 & -0.733 \\
\hline & $(0.135)^{* * *}$ & $(0.141)^{* * *}$ & $*(0.137) * * *$ & $(0.019)^{* * *}$ & ${ }^{k}(0.020)^{* *}$ & $*(0.018)^{* * *}$ & $(0.102)^{* * *}$ & $*(0.086)^{* * *}$ & * $(0.087)^{* * *}$ \\
\hline & {$[0.082]^{* * *}$} & ${ }^{k}[0.084]^{* * *}$ & $*[0.080]^{* * *}$ & {$[[0.018] * * *$} & ${ }^{k}[0.019]^{* *}$ & $*[0.020] * * *$ & {$[0.080]^{* * *}$} & $*[0.071]^{* * *}$ & $*[0.071] * * *$ \\
\hline \multirow{3}{*}{$(\Delta F R / R M)($ DumBreak $)$} & -0.183 & -0.082 & 0.039 & -0.025 & -0.022 & -0.021 & -0.152 & -0.200 & -0.314 \\
\hline & $(0.134)$ & $(0.147)$ & $(0.138)$ & $(0.014)^{*}$ & $(0.013)^{*}$ & $(0.019)$ & $(0.098)$ & $(0.081)^{* *}$ & $(0.098)^{* * *}$ \\
\hline & {$[0.091]^{* *}$} & [0.097] & [0.099] & [0.019] & {$[0.018]$} & {$[0.023]$} & {$[0.088]^{*}$} & {$[0.078]^{* *}$} & {$[0.101]^{* * *}$} \\
\hline \multirow[t]{3}{*}{$\Delta \ln (I N F L)$} & 2.719 & 4.623 & 5.152 & 1.274 & 0.534 & 0.562 & 0.462 & 0.422 & 0.486 \\
\hline & (2.438) & $(1.795)^{* *}$ & $(1.690)^{* * *}$ & $(0.620)^{* *}$ & (0.673) & $(0.497)$ & $(0.214)^{* *}$ & $(0.169)^{* *}$ & $(0.171)^{* * *}$ \\
\hline & [1.875] & {$[1.975]^{* *}$} & {$[1.875]^{* * *}$} & {$[0.606]^{* *}$} & {$[0.640]$} & [0.739] & {$[0.220]^{* *}$} & {$[0.194]^{* *}$} & {$[0.195]^{* *}$} \\
\hline \multirow[t]{3}{*}{$\Delta \ln (I N F L)($ DumBreak $)$} & & & -7.55 & & & -0.104 & & & 0.854 \\
\hline & & & $(2.551)^{* * *}$ & & & (1.995) & & & $(0.445)^{*}$ \\
\hline & & & {$[2.280]^{* * *}$} & & & [1.313] & & & {$[0.492]^{*}$} \\
\hline \multirow[t]{3}{*}{$\Delta \ln (R G N P)$} & & 2.395 & 1.783 & & 0.691 & 0.688 & & 0.596 & 0.629 \\
\hline & & $(1.029)^{* *}$ & (1.168) & & $(0.225)^{* *}$ & $*(0.229)^{* * *}$ & & $(0.098)^{* * *}$ & $*(0.108)^{* * *}$ \\
\hline & & {$[0.961]^{* *}$} & {$[0.928]^{*}$} & & {$[0.246]^{* *}$} & $*[0.250]^{* * *}$ & & {$[0.119]^{* * *}$} & $*[0.119] * * *$ \\
\hline$H_{0}: \beta_{0}=-1$ & 1.049 & 0.244 & 0.083 & $4.518^{* *}$ & 1.281 & 1.476 & 3.266 & $8.403^{* * *}$ & $9.423^{* * *}$ \\
\hline
\end{tabular}




\begin{tabular}{|c|c|c|c|c|c|c|c|c|c|}
\hline$H_{0}: \beta_{0}+\beta_{1}=-1$ & $3.406 *$ & 0.175 & $5.859 * *$ & 1.256 & 0.001 & 0.003 & 0.545 & 1.397 & 0.696 \\
\hline Adjusted R-squared & 0.831 & 0.840 & 0.857 & 0.984 & 0.985 & 0.985 & 0.855 & 0.888 & 0.890 \\
\hline Break date & \multicolumn{3}{|c|}{1998 Q4 } & \multicolumn{3}{|c|}{1998 Q4 } & \multicolumn{3}{|c|}{2000 Q4 } \\
\hline Sample period & \multirow{2}{*}{\multicolumn{3}{|c|}{1985 Q1 - 2007Q2 }} & \multicolumn{3}{|c|}{1985 Q1 - 2007 Q2 } & \multicolumn{3}{|c|}{1985 Q1 - 2006 Q4 } \\
\hline Observations & & \multicolumn{2}{|c|}{90} & \multicolumn{3}{|c|}{90} & \multicolumn{3}{|c|}{88} \\
\hline
\end{tabular}

Panel C. Selected Latin American Countries

\begin{tabular}{|c|c|c|c|c|c|c|c|c|c|}
\hline \multirow[b]{2}{*}{ Explanatory Variable } & \multicolumn{3}{|c|}{ Argentina } & \multicolumn{3}{|c|}{ Brazil } & \multicolumn{3}{|c|}{ Mexico } \\
\hline & (1) & $(2)$ & (3) & (1) & (2) & (3) & $(1)$ & $(2)$ & (3) \\
\hline \multirow[t]{3}{*}{$\Delta F R / R M$} & -0.956 & -1.032 & -1.04 & -0.932 & -0.69 & -0.736 & -0.975 & -0.975 & -0.976 \\
\hline & $(0.040)^{* * *}$ & ${ }^{k}(0.054)^{* * *}$ & $(0.055)^{* * *}$ & $(0.164)^{* *}$ & $\leqslant *(0.165)^{* * *}$ & ${ }^{*}(0.171)^{* * *}$ & $(0.019)^{* *}$ & $k *(0.019)^{* * *}$ & $*(0.019)^{* * *}$ \\
\hline & {$[0.026]^{* * *}$} & ${ }^{*}[0.042]^{* * *}$ & {$[0.041] * * *$} & {$[0.167]^{* *}$} & $\leqslant *[0.167]^{* * *}$ & ${ }^{*}[0.164]^{* * *}$ & {$[0.017]^{* *}$} & $k *[0.017] * * *$ & $*[0.016] * * *$ \\
\hline \multirow{3}{*}{$(\Delta F R / R M)($ DumBreak $)$} & -0.145 & -0.262 & 0.837 & -0.285 & -0.130 & 0.044 & -0.067 & -0.059 & -0.174 \\
\hline & $(0.097)$ & $(0.113)^{* *}$ & $(0.345)^{* *}$ & $(0.246)$ & $(0.216)$ & $(0.227)$ & $(0.040)^{*}$ & $(0.050)$ & $(0.063)^{* * *}$ \\
\hline & {$[0.125]$} & {$[0.131]^{*}$} & {$[-0.679]$} & {$[0.281]$} & {$[0.258]$} & {$[0.268]$} & {$[0.048]$} & {$[0.050]$} & {$[0.064]^{* * *}$} \\
\hline \multirow[t]{3}{*}{$\Delta \ln (I N F L)$} & 1.713 & 1.377 & 1.352 & 0.603 & 1.077 & 1.017 & 0.561 & 0.566 & 0.582 \\
\hline & $(0.275)^{* * *}$ & ${ }^{*}(0.334)^{* * *}$ & $(0.338) * * *$ & $(0.875)$ & $(0.904)$ & $-0.838)$ & $(0.079)^{* *}$ & $k *(0.081)^{* * *}$ & $*(0.081)^{* * *}$ \\
\hline & {$[0.329]^{* * *}$} & ${ }^{*}[0.350]^{* * *}$ & * $[0.345] * * *$ & {$[0.524]$} & {$[0.494]^{* *}$} & {$[0.481]^{* *}$} & {$[0.055]^{* *}$} & $k *[0.056]^{* * *}$ & $*[0.054]^{* * *}$ \\
\hline \multirow[t]{3}{*}{$\Delta \ln (I N F L)($ DumBreak $)$} & & & -7.488 & & & -2.448 & & & 0.862 \\
\hline & & & $(2.415)^{* * *}$ & & & $(0.937)^{* *}$ & & & $(0.399)^{* *}$ \\
\hline & & & {$[4.540]$} & & & {$[1.309]^{*}$} & & & {$[0.313]^{* * *}$} \\
\hline \multirow[t]{3}{*}{$\Delta \ln (R G N P)$} & & 2.184 & 2.434 & & -13.796 & -11.265 & & 0.208 & 0.456 \\
\hline & & $(1.031)^{* *}$ & $(1.052)^{* *}$ & & $(3.838)^{* * *}$ & $*(4.258)^{* *}$ & & $(0.488)$ & $(0.448)$ \\
\hline & & {$[0.958]^{* *}$} & {$[0.956]^{* *}$} & & {$[4.124] * * *$} & ${ }^{*}[4.233]^{* *}$ & & {$[0.368]$} & [0.365] \\
\hline$H_{0}: \beta_{0}=-1$ & 1.201 & 0.343 & 0.534 & 0.172 & 3.525 & 2.398 & 1.677 & 1.785 & 1.594 \\
\hline$H_{0}: \beta_{0}+\beta_{1}=-1$ & 1.366 & $5.071^{* *}$ & $5.570 * *$ & 2.152 & 1.857 & $4.740 *$ & 1.471 & 0.567 & $6.293^{* *}$ \\
\hline Adjusted R-squared & 0.965 & 0.967 & 0.968 & 0.593 & 0.669 & 0.686 & 0.981 & 0.980 & 0.982 \\
\hline Breakdate & & 2004 Q3 & & & 2003 Q3 & & & 1996 Q4 & \\
\hline Sample period & & $92 \mathrm{Q} 1-200$ & 7 Q2 & & 995 Q2 - 200 & 7 Q2 & & 985 Q1 - 200 & 07 Q2 \\
\hline Observations & & 62 & & & 49 & & & 90 & \\
\hline
\end{tabular}

Note: The table reports coefficients of regressing central bank net domestic credit on foreign reserves, measured as 4 quarter changes, scaled by lagged reserve money stock $(R M) . \Delta \ln (I N F L)$ is the 4 quarter percent change in the CPI, $\Delta \ln (R G N P)$ is the 4 quarter change in real GDP, and DumBreak is a dummy variable denoting break point in sterilization behavior. Constant not reported. Huber-White standard errors in parentheses; Newey-West standard errors adjusted for serial correlation up to three quarters in square brackets. Significance at $1 \%, 5 \%, 10 \%$ indicated by ***, **, and *, respectively. 
Table 3. Balance of Payments Inflows to Emerging Markets, Annual Averages, in billions U.S.\$

\begin{tabular}{|c|c|c|c|c|c|c|c|c|c|c|c|c|c|c|c|c|}
\hline & \multicolumn{4}{|c|}{$\begin{array}{c}\text { Current Account } \\
\text { Balance }\end{array}$} & \multicolumn{4}{|c|}{$\begin{array}{c}\text { Net Foreign } \\
\text { Direct Investment }\end{array}$} & \multicolumn{4}{|c|}{$\begin{array}{l}\text { Net non-Foreign } \\
\text { Direct Investment }\end{array}$} & \multicolumn{4}{|c|}{ Reserve Inflows } \\
\hline & $\begin{array}{c}1985- \\
89\end{array}$ & $\begin{array}{c}1990- \\
93\end{array}$ & $\begin{array}{c}1995- \\
96\end{array}$ & $\begin{array}{c}2000 \\
-06\end{array}$ & $\begin{array}{c}1985- \\
89 \\
\end{array}$ & $\begin{array}{c}1990- \\
93\end{array}$ & $\begin{array}{c}1995- \\
96\end{array}$ & $\begin{array}{c}2000 \\
-06\end{array}$ & $\begin{array}{c}1985- \\
89\end{array}$ & $\begin{array}{c}1990- \\
93\end{array}$ & $\begin{array}{c}1995- \\
96\end{array}$ & $\begin{array}{c}2000 \\
-06\end{array}$ & $\begin{array}{c}1985- \\
89\end{array}$ & $\begin{array}{c}1990- \\
93\end{array}$ & $\begin{array}{c}1995- \\
96\end{array}$ & $\begin{array}{c}2000 \\
-06\end{array}$ \\
\hline Asia & 7 & -3 & -26 & 206 & 5 & 18 & 49 & 81 & 9 & 20 & 53 & -34 & 18 & 28 & 49 & 250 \\
\hline China & -5 & 5 & 4 & 100 & 2 & 9 & 36 & 58 & 5 & 0 & 3 & -8 & 1 & 6 & 27 & 152 \\
\hline India & -6 & -4 & -6 & -1 & 0 & 0 & 2 & 5 & 5 & 5 & 6 & 14 & -1 & 2 & 0 & 20 \\
\hline Korea & 7 & -3 & -16 & 14 & 0 & 0 & -2 & 1 & -4 & 5 & 23 & 10 & 3 & 1 & 4 & 25 \\
\hline Taiwan & 13 & 10 & 8 & 24 & -2 & -2 & -2 & -4 & 0 & -5 & -7 & 2 & 11 & 2 & -1 & 24 \\
\hline Other Asia & -2 & -10 & -17 & 69 & 4 & 11 & 15 & 20 & 2 & 16 & 28 & -52 & 5 & 17 & 19 & 29 \\
\hline Latin America & -7 & -21 & -34 & 6 & 5 & 9 & 31 & 51 & -19 & 25 & 22 & -29 & -1 & 18 & 24 & 20 \\
\hline Argentina & -2 & -2 & -6 & 4 & 1 & 2 & 5 & 4 & -2 & 3 & 4 & -11 & 0 & 3 & 2 & 1 \\
\hline Brazil & 0 & 0 & -21 & -2 & 1 & 1 & 8 & 15 & -11 & 0 & 24 & -3 & 0 & 6 & 11 & 8 \\
\hline Mexico & -1 & -18 & -2 & -12 & 2 & 4 & 9 & 20 & -3 & 20 & -8 & 1 & 0 & 5 & 6 & 6 \\
\hline Other LA & -3 & -1 & -5 & 16 & 1 & 2 & 9 & 11 & -3 & 2 & 2 & -15 & -1 & 5 & 5 & 6 \\
\hline Central Europe & -2 & -3 & -6 & -20 & 0 & 2 & 10 & 19 & -4 & -2 & 7 & 7 & 0 & 3 & 11 & 6 \\
\hline Russia & & & 9 & 64 & & & 2 & 1 & & & -14 & -5 & & & 4 & 46 \\
\hline Middle East & -5 & -22 & 5 & 86 & -1 & 1 & -2 & -1 & 3 & 26 & 4 & -61 & -3 & -2 & 5 & 13 \\
\hline Total & -6 & -48 & -52 & 342 & 9 & 30 & 90 & 151 & -11 & 70 & 71 & -122 & 14 & 47 & 92 & 335 \\
\hline
\end{tabular}

Notes: Net non-foreign direct investment inflows include portfolio and other capital flows in the financial account. Other Asia includes Hong Kong, Indonesia, Malaysia, the Philippines, Singapore, and Thailand. Other Latin America includes Chile, Colombia, Peru, and Venezuela. Central Europe includes Czech Republic, Hungary, and Poland. Middle East includes Kuwait, Libya, Oman, Qatar, and Saudi Arabia.. Blank cells indicate values less than \$500 million. Source: IMF Balance of Payments Statistics. 
Table 4. Does Sterilization Depend on the Composition of Balance of Payments Inflows?

$\Delta D C / R M_{-4}=\alpha+\beta_{0} \sum_{k=1}^{4} C A_{-k} / R M_{-4}+\beta_{1} \sum_{k=1}^{4} N F D I_{-k} / R M_{-4}+\beta_{2} \sum_{k=1}^{4} n o n-N F D I_{-k} / R M_{-4}+\beta_{3} \Delta \ln (G N P)$

$+\beta_{0}^{\prime}\left(\sum_{k=1}^{4} C A_{-k} / R M_{-4}\right)($ Dum Break $)+\beta_{1}^{\prime}\left(\sum_{k=1}^{4} N F D I_{-k} / R M_{-4}\right)($ DumBreak $)+\beta_{2}^{\prime}\left(\sum_{k=1}^{4}\right.$ non $\left.-N F D I_{-k} / R M_{-4}\right)\left(\right.$ DumBreak $^{2}$

Panel A. Selected Asian Countries

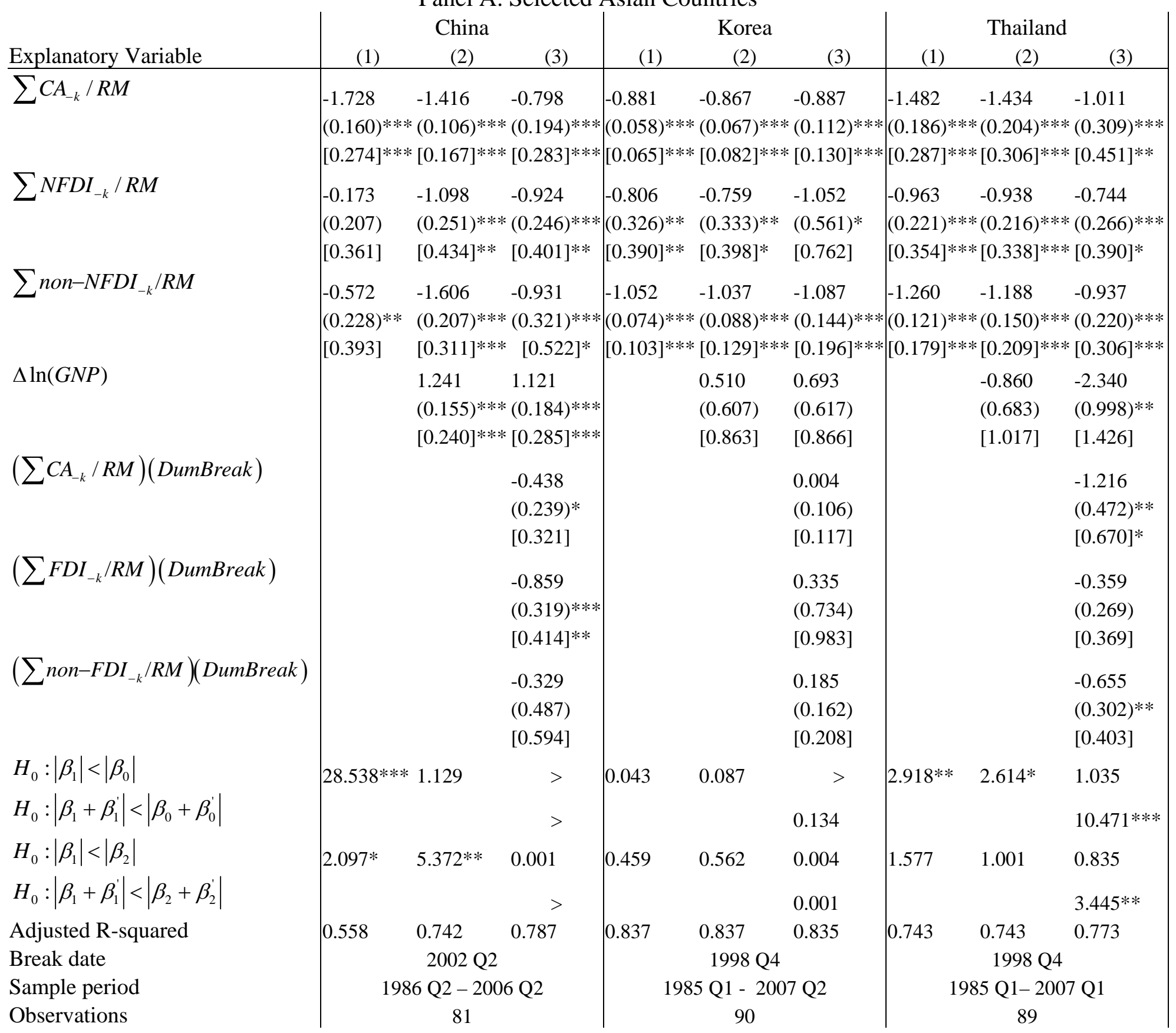


Table 4. Does Sterilization Depend on the Composition of Balance of Payments Inflows? (cont'd)

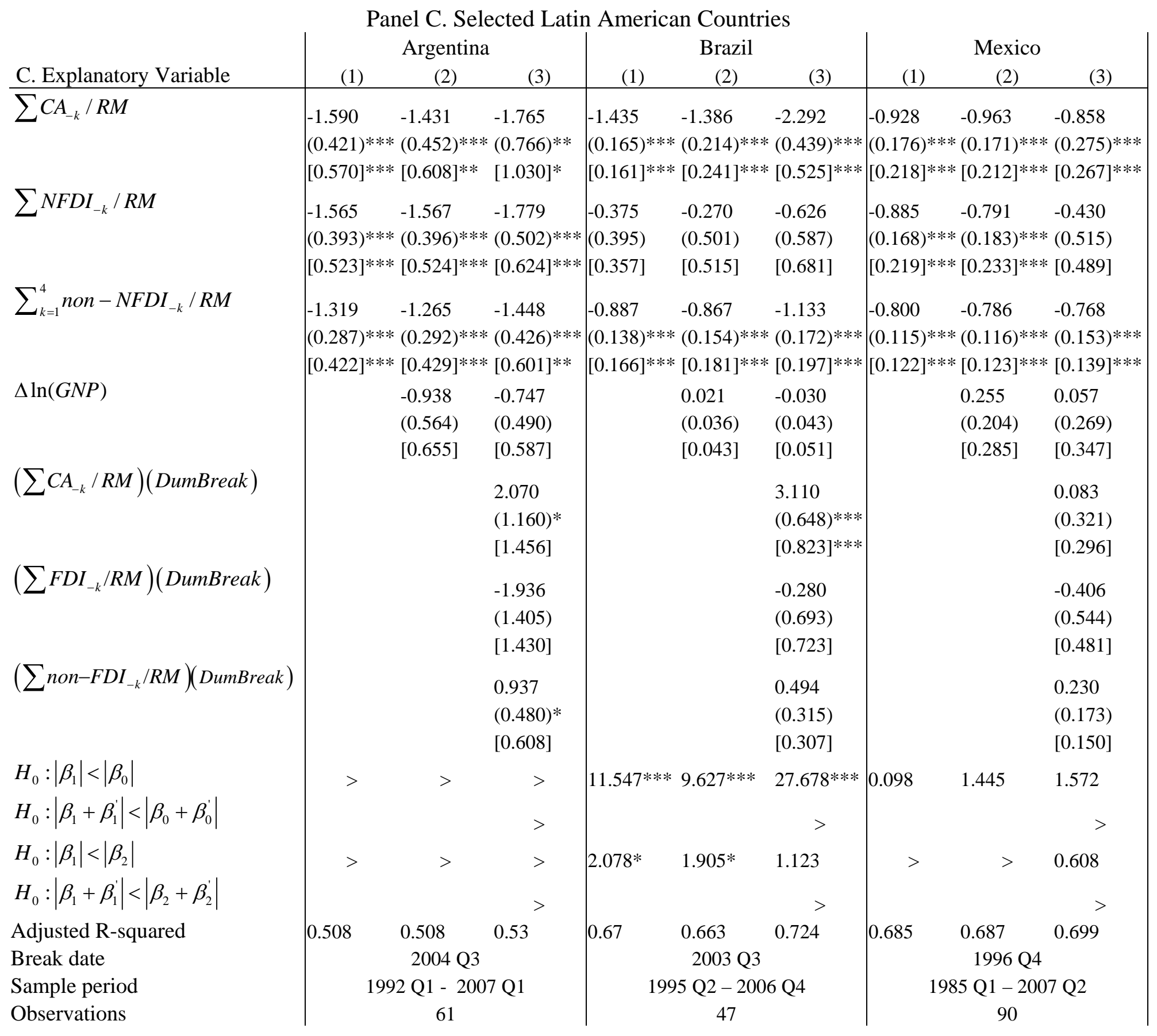

Note: The table reports coefficients of regressing central bank net domestic credit on 4-quarter cumulative current account surplus (CA), net foreign direct investment inflows (NFDI), and non-NFDI capital inflows (non-NFDI) expressed in local currency terms, all scaled by the lagged reserve money stock $(R M) . \Delta \ln (G N P)$ is the 4 quarter percent change in nominal GDP, and DumBreak is a dummy variable denoting break point in sterilization behavior. Huber-White standard errors in parentheses; Newey-West standard errors adjusted for serial correlation up to three quarters in square brackets. F statistic for null inequality hypotheses, with one-tail significance test results; results not reported when (the absolute value of the) coefficient on FDI inflows exceeds that on current account surplus or non-FDI inflows, as indicated by “>”. Constant not reported. Significance at 1\%, 5\%, 10\% indicated by ***, **, and *, respectively. 


\section{Figure 1a: The Trilemma Framework}

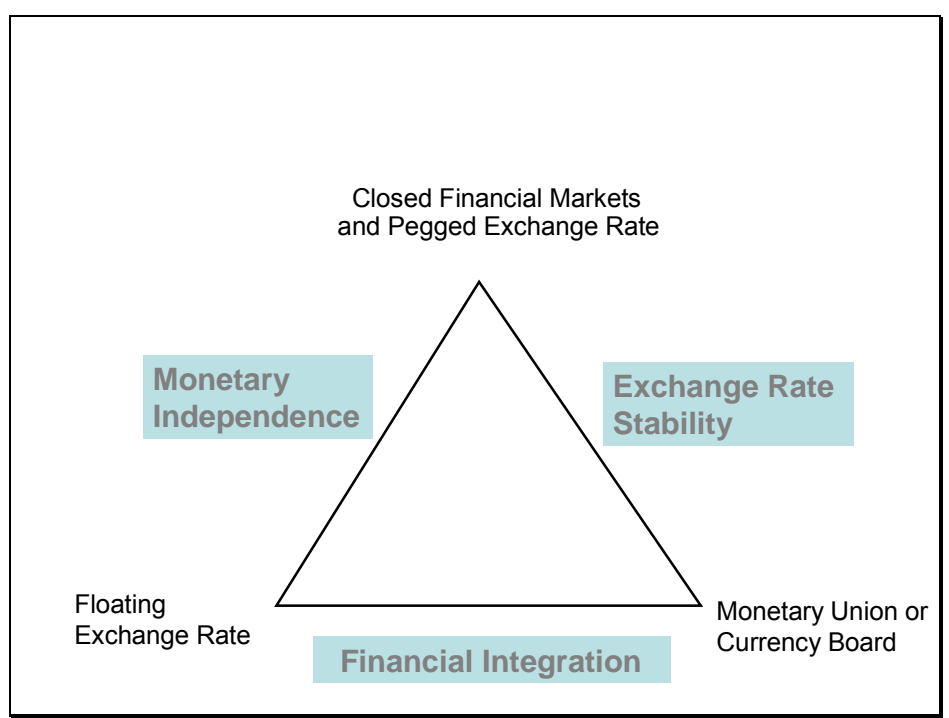

Figure 1b: Unstable Trilemma Configurations

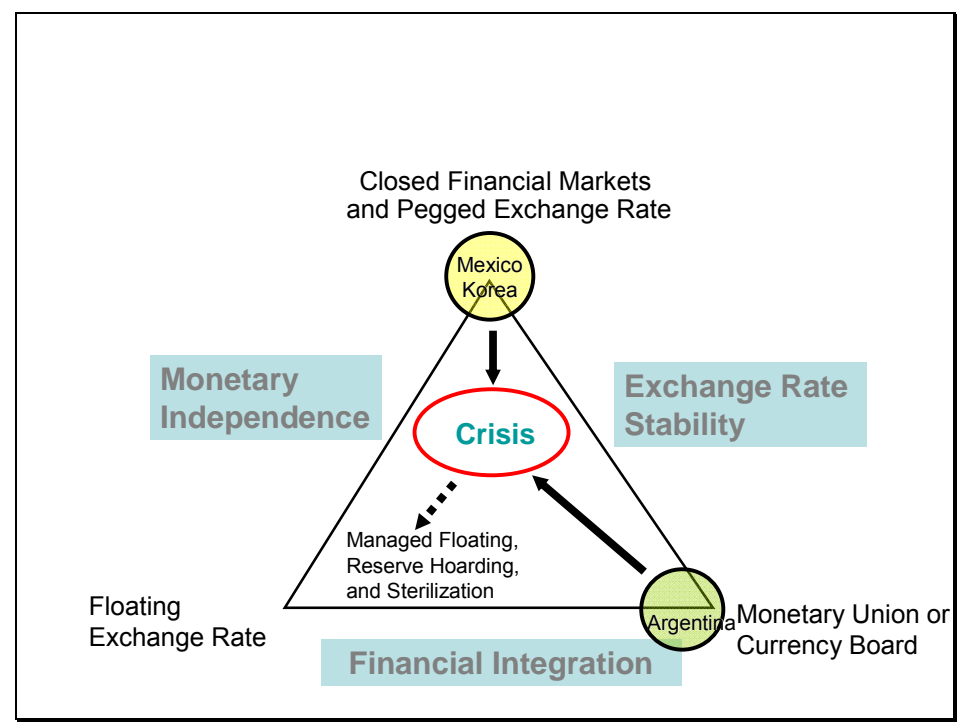

Note: Argentina, Korea, and Mexico (and other countries) experienced financial crises in the 1990s as they became more integrated with global financial markets and converged to policy configurations involving greater exchange rate flexibility, reserve hoarding, and sterilization in the aftermath of their respective crises. 
Figure 2. Net Foreign Reserve and Net Domestic Credit Changes of Central Bank, (4 quarter changes relative to stock of reserve money lagged 4Q, in percent)

Panel A. Selected Asian Countries

CHINA

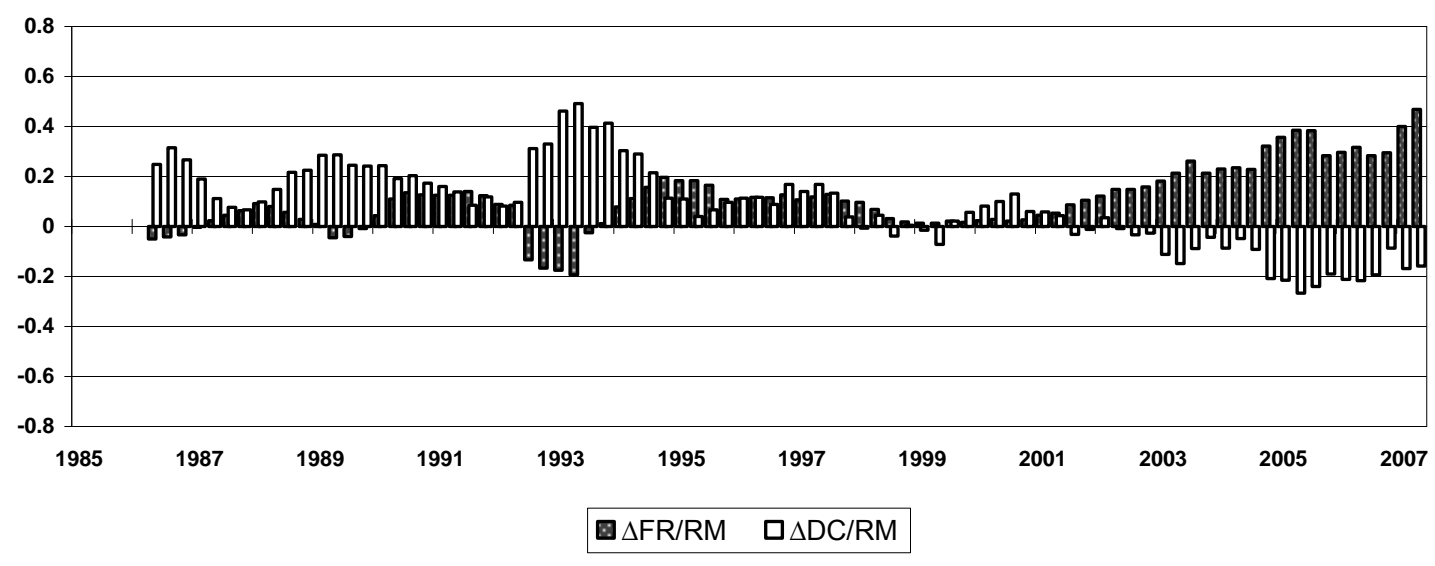

KOREA

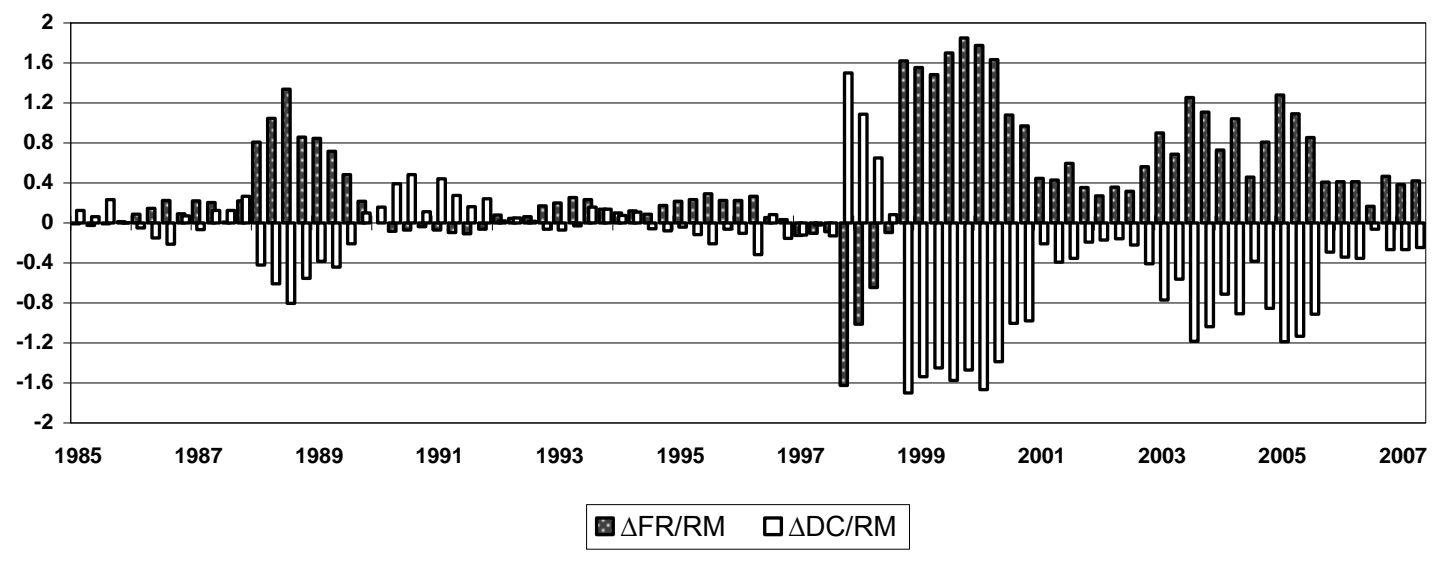

THAILAND

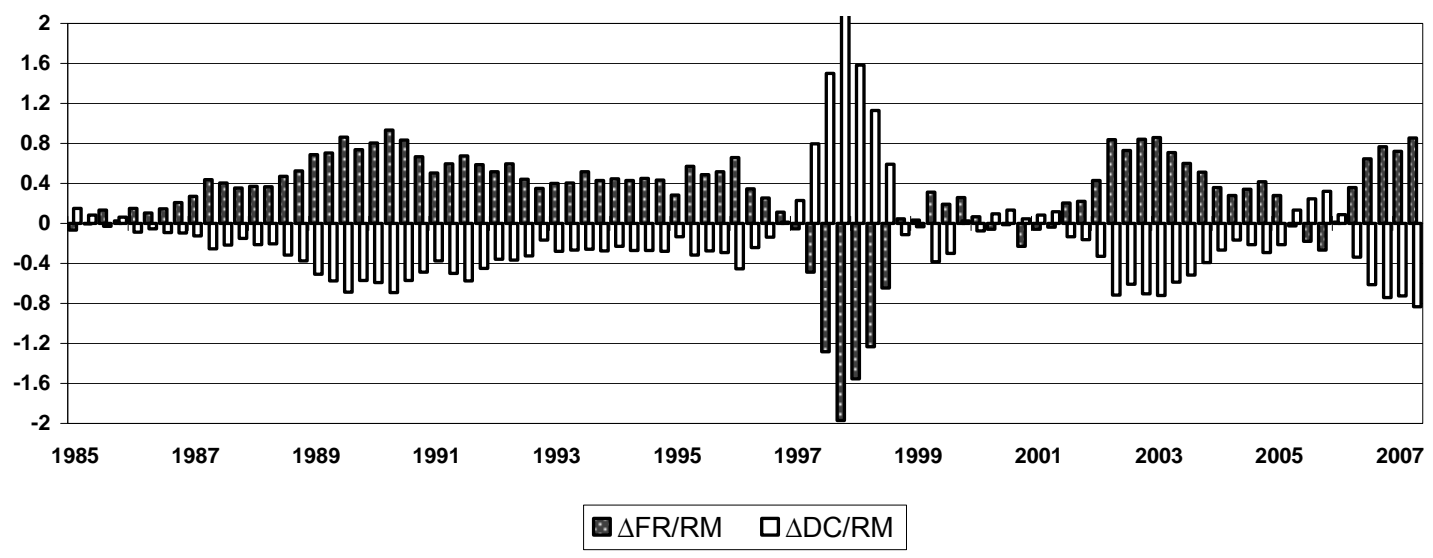

Note: positive values correspond to foreign reserve inflows or domestic credit increases. 
Figure 2. Net Foreign Reserves and Net Domestic Credit Changes of Central Bank,

(4 quarter changes relative to stock of reserve money lagged $4 \mathrm{Q}$, in percent)

Panel B: Other Selected Asian Countries

MALAYSIA

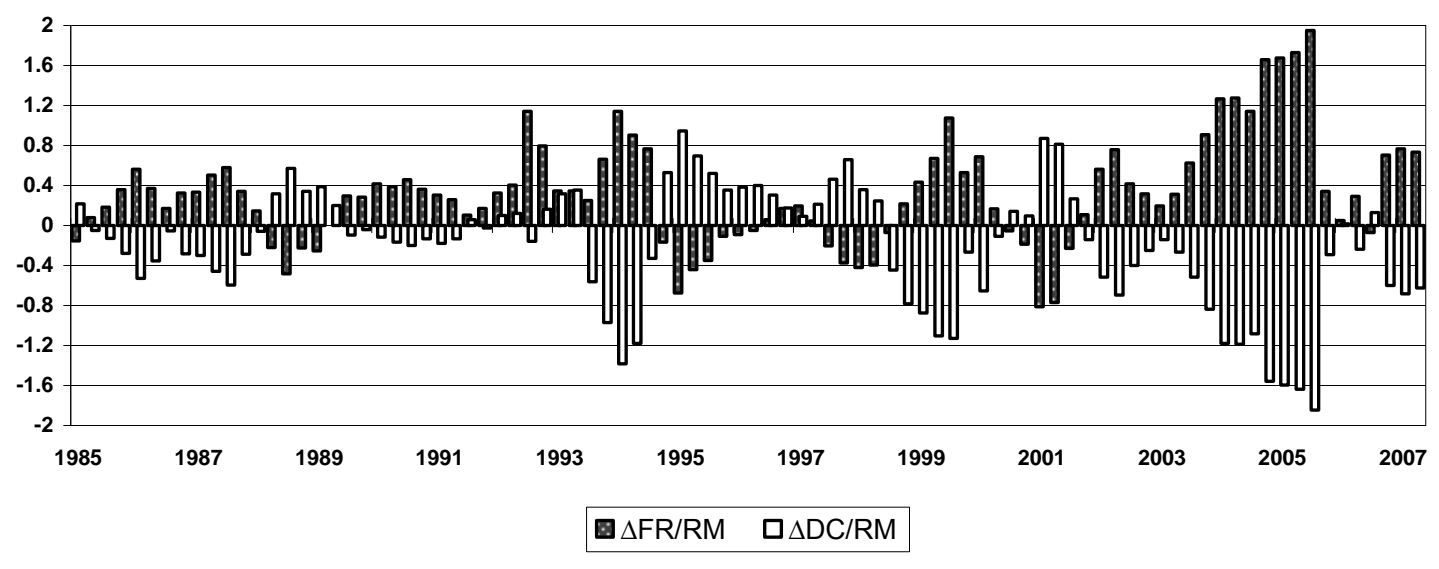

SINGAPORE

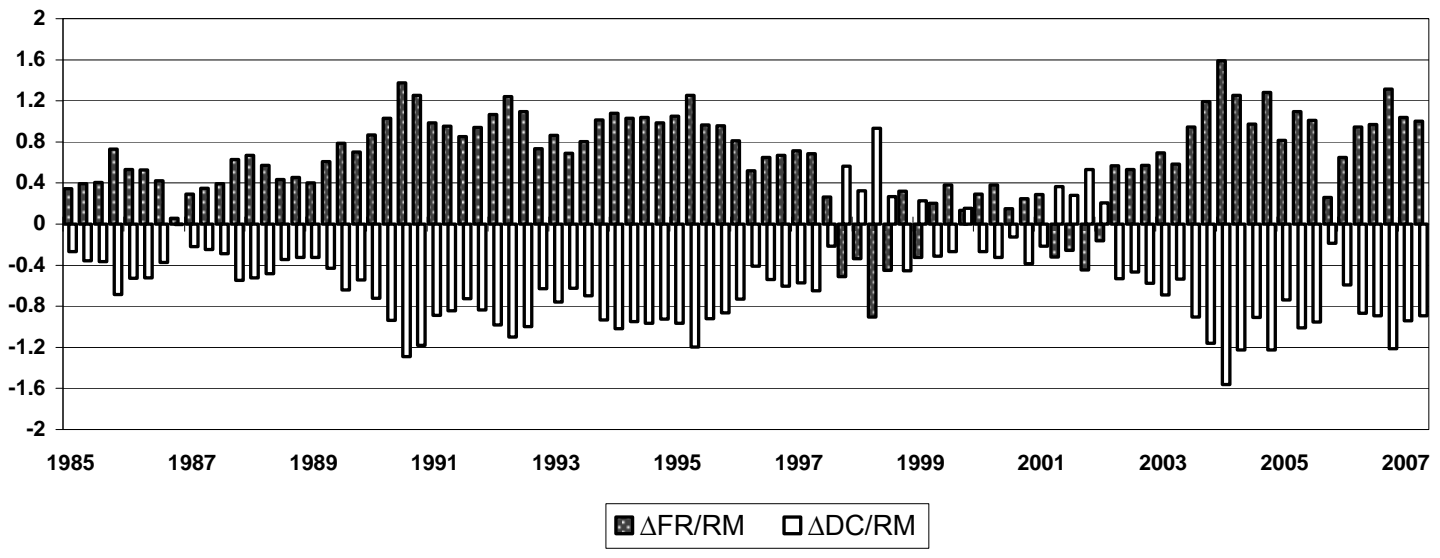

INDIA

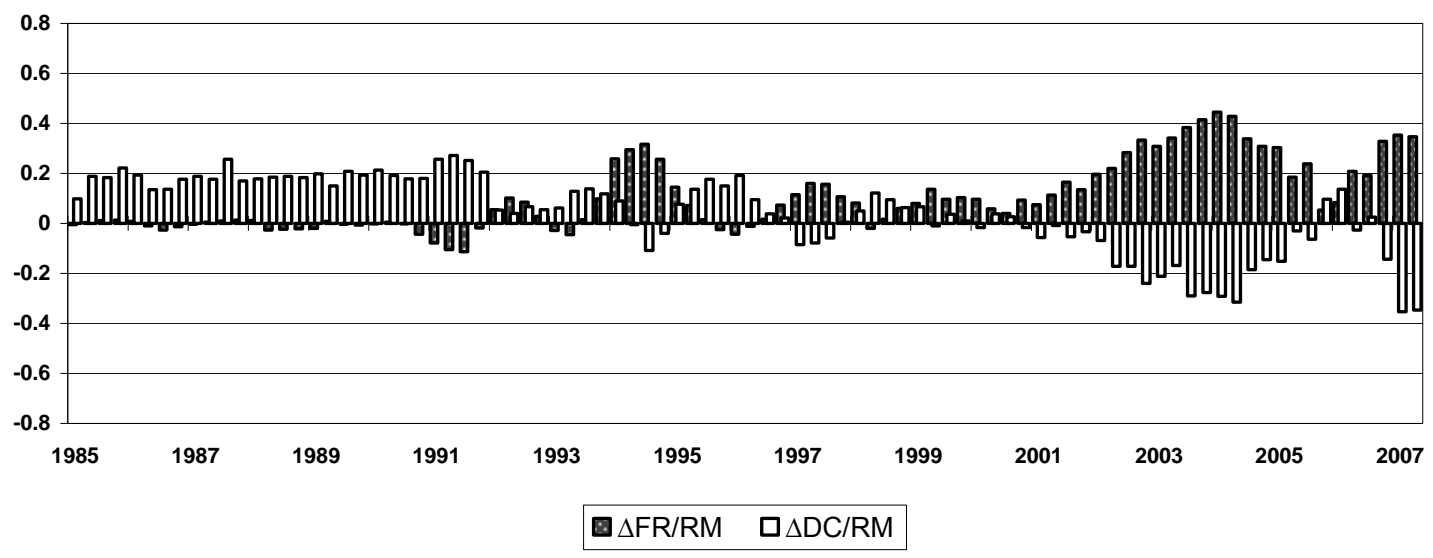

Note: positive values correspond to foreign reserve inflows or domestic credit increases. 
Figure 2. Net Foreign Reserves and Net Domestic Credit Changes of Central Bank (4 quarter changes relative to stock of reserve money lagged 4Q, in percent)

Panel C: Selected Latin American Countries

ARGENTINA

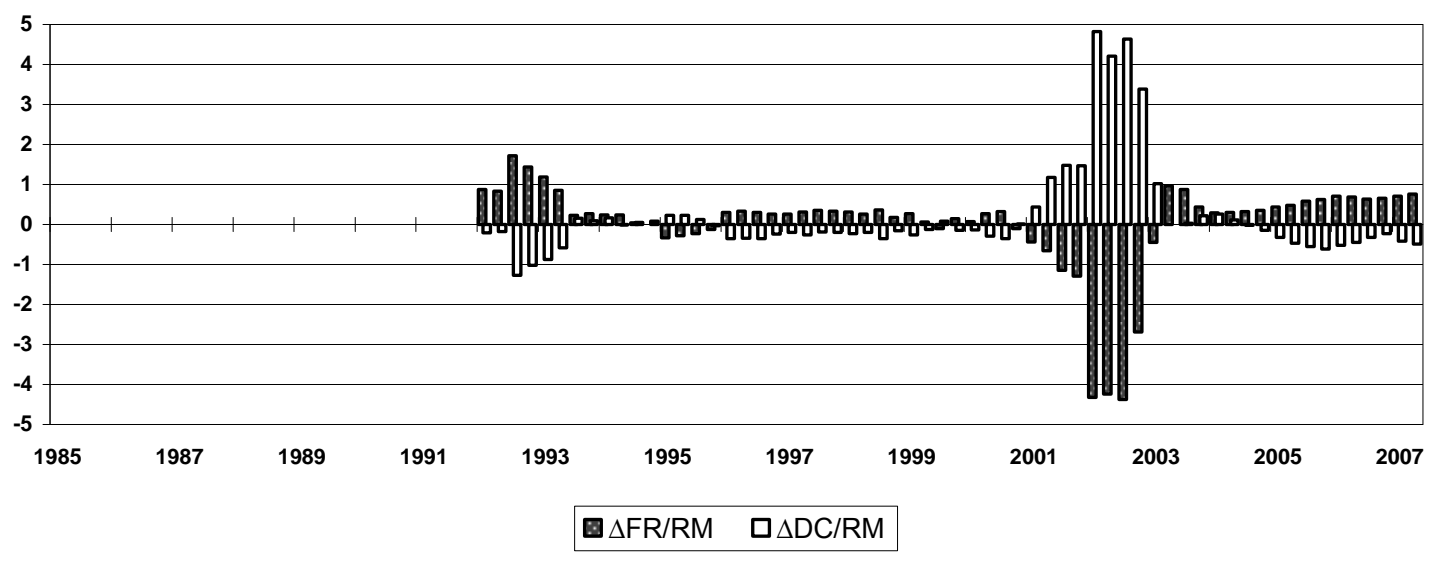

BRAZIL

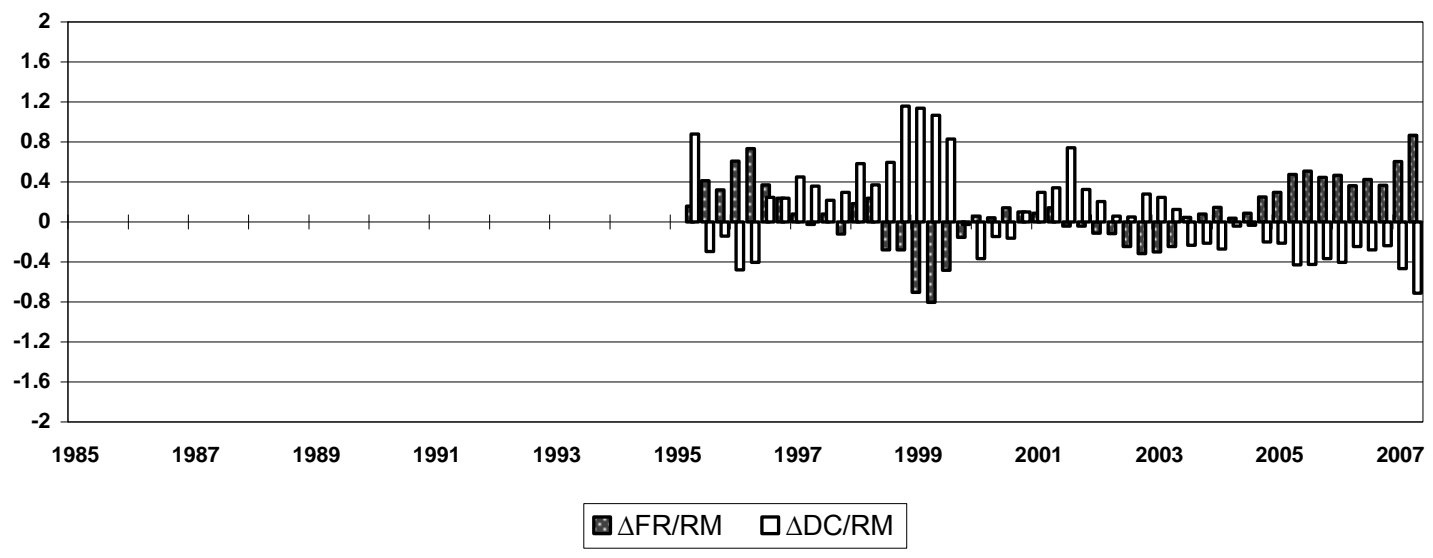

MEXICO

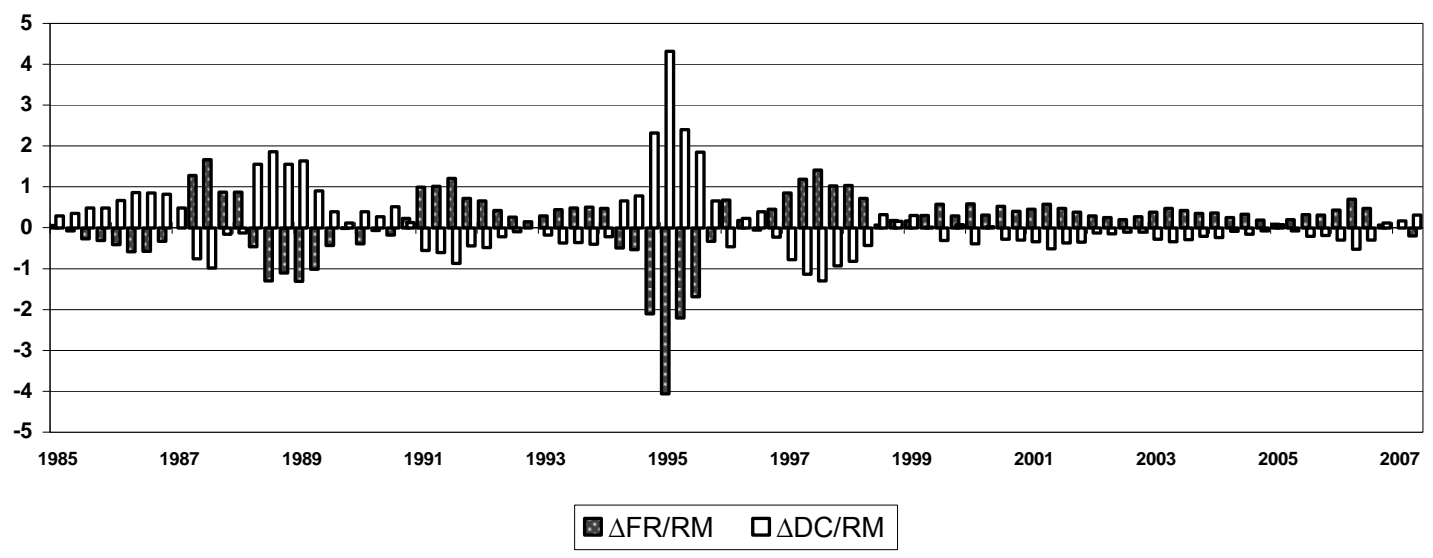

Note: positive values correspond to foreign reserve inflows or domestic asset increases. 
Figures 3. Sterilization Coefficients from 40-quarter Rolling Regressions

\section{Panel A: Selected Asian Countries}

\section{CHINA}

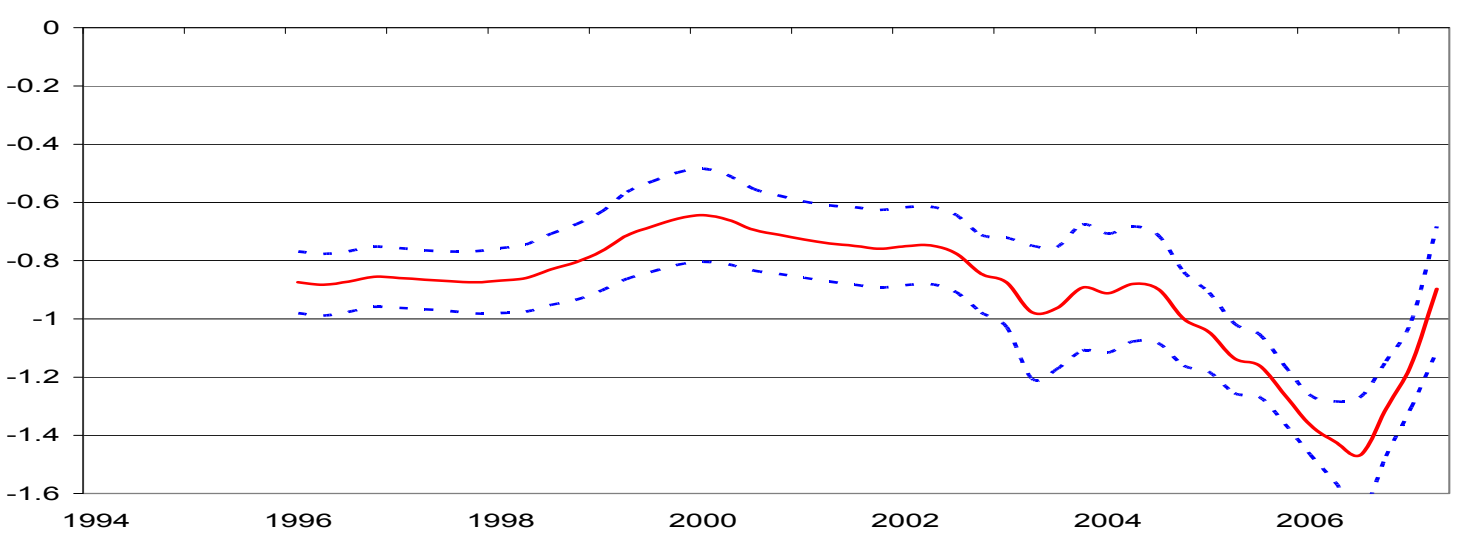

KOREA

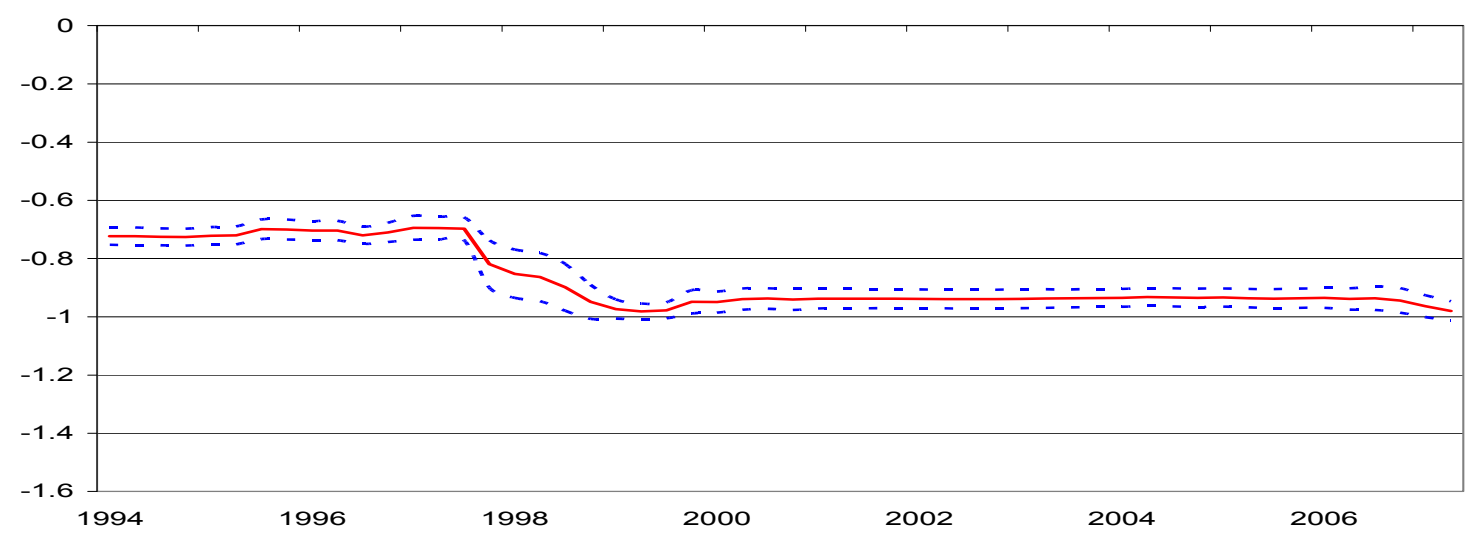

THAILAND

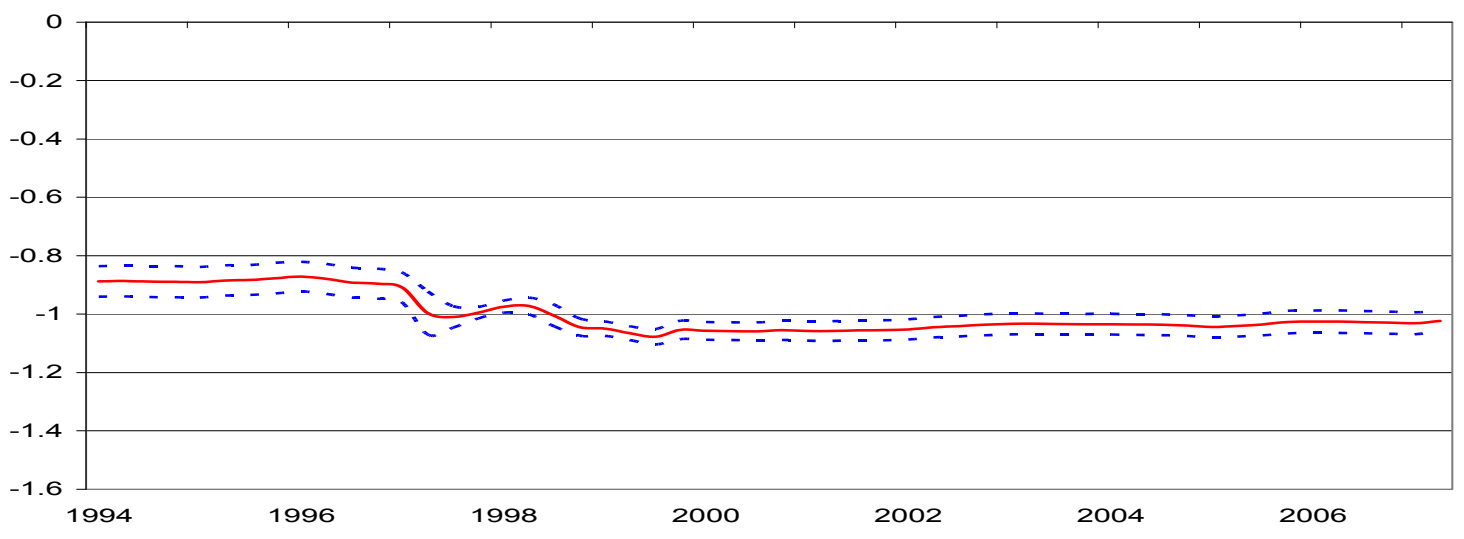


Figures 3. Sterilization Coefficients from 40-quarter Rolling Regressions

\section{Panel B: Other Selected Asian Countries}

MALAYSIA

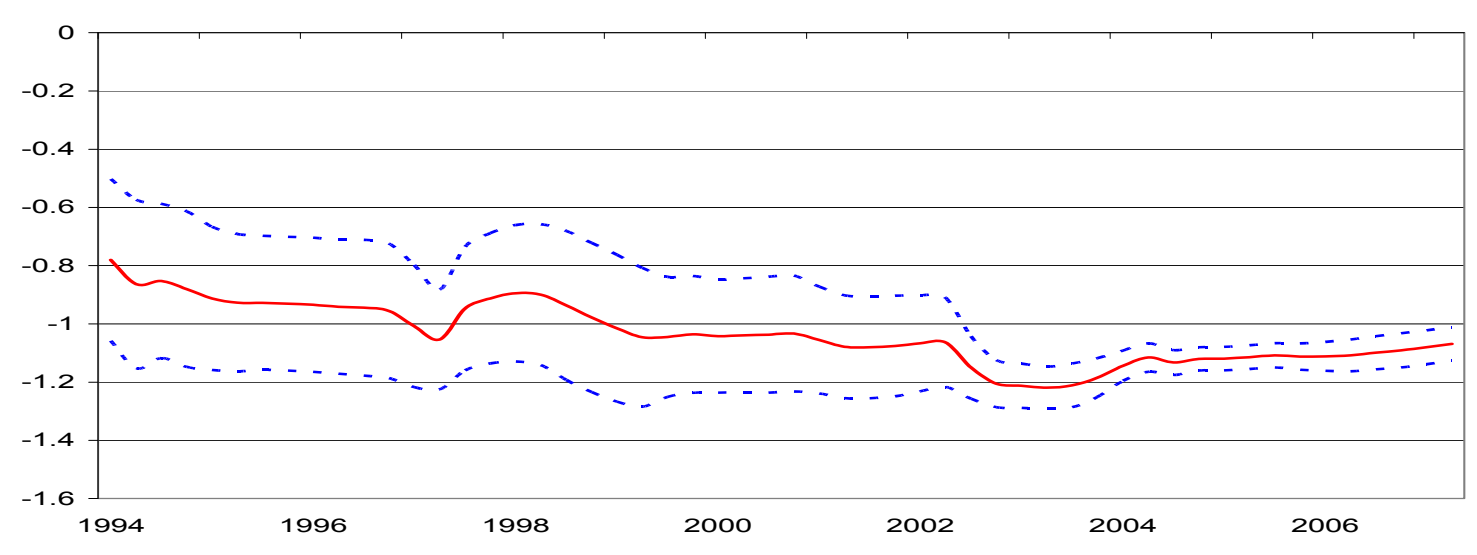

SINGAPORE
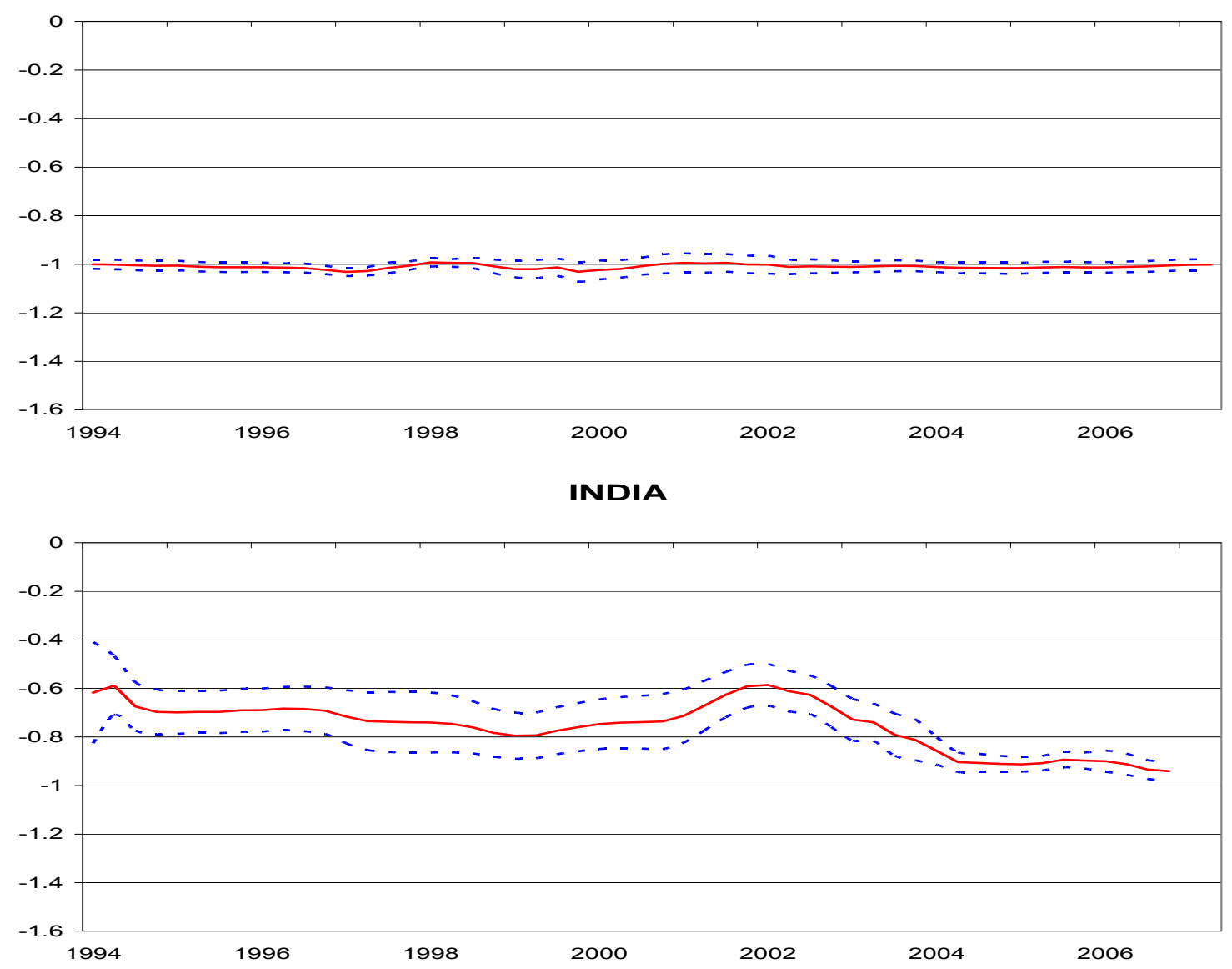
Figures 3. Sterilization Coefficients from 40-quarter Rolling Regressions

Panel C: Selected Latin American Countries

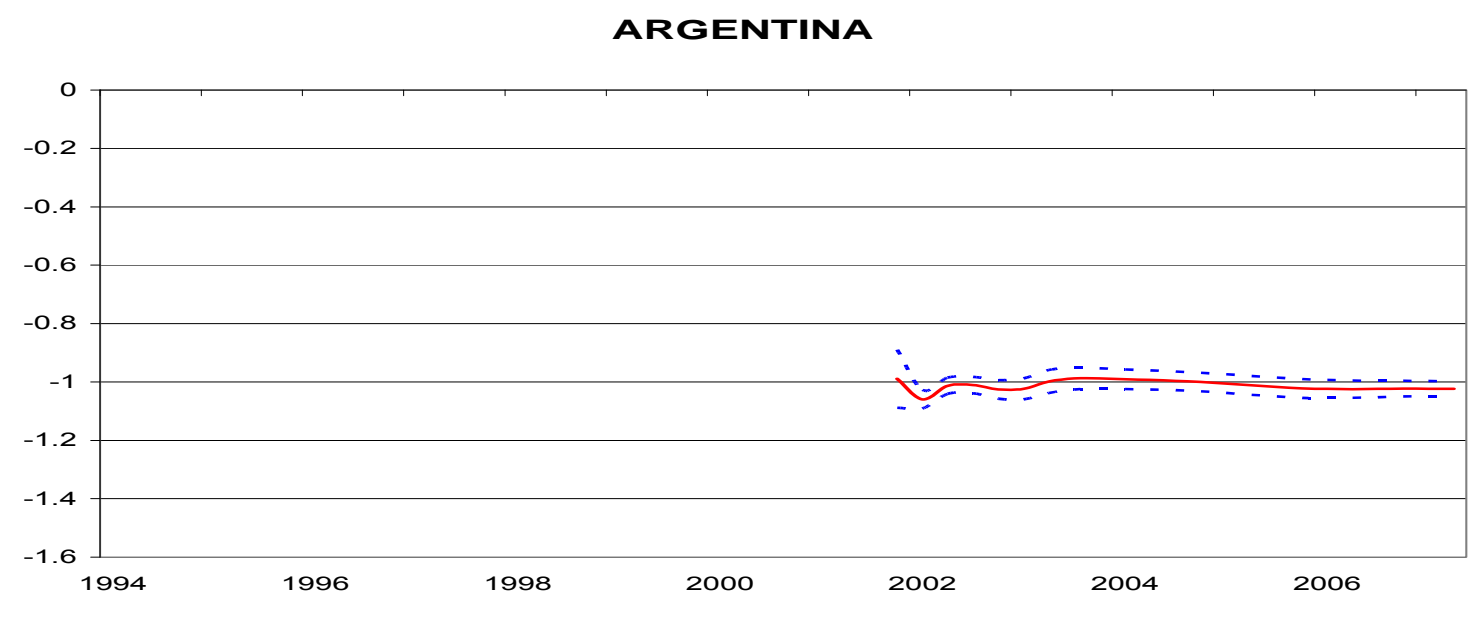

BRAZIL

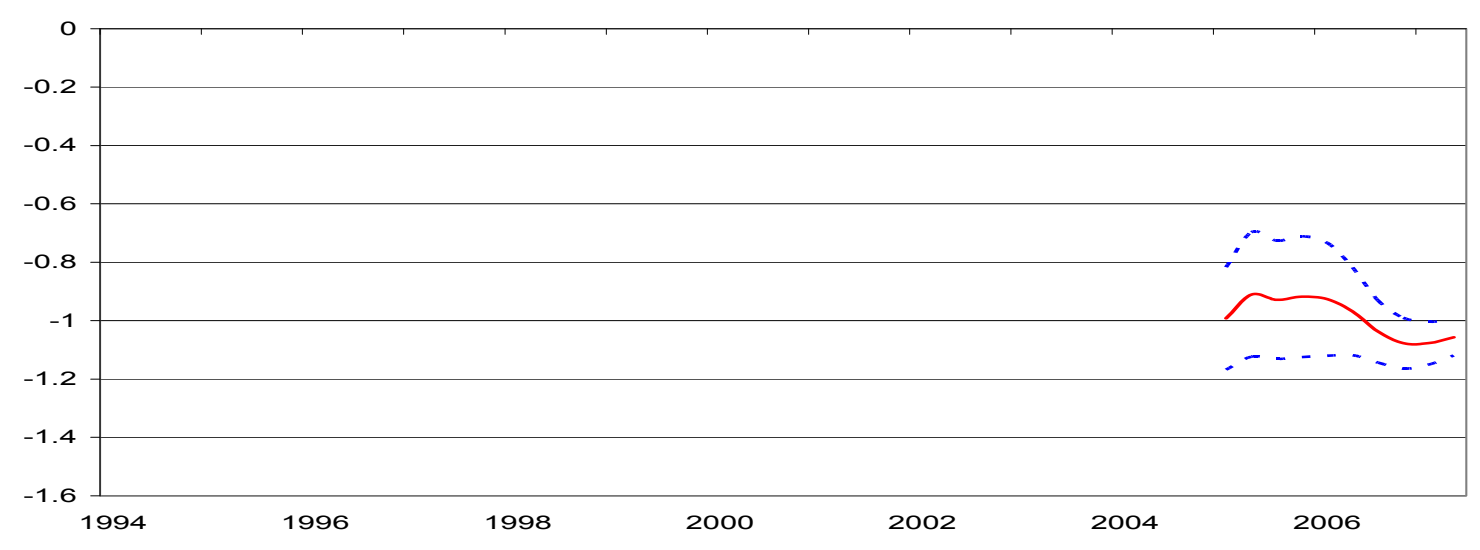

MEXICO

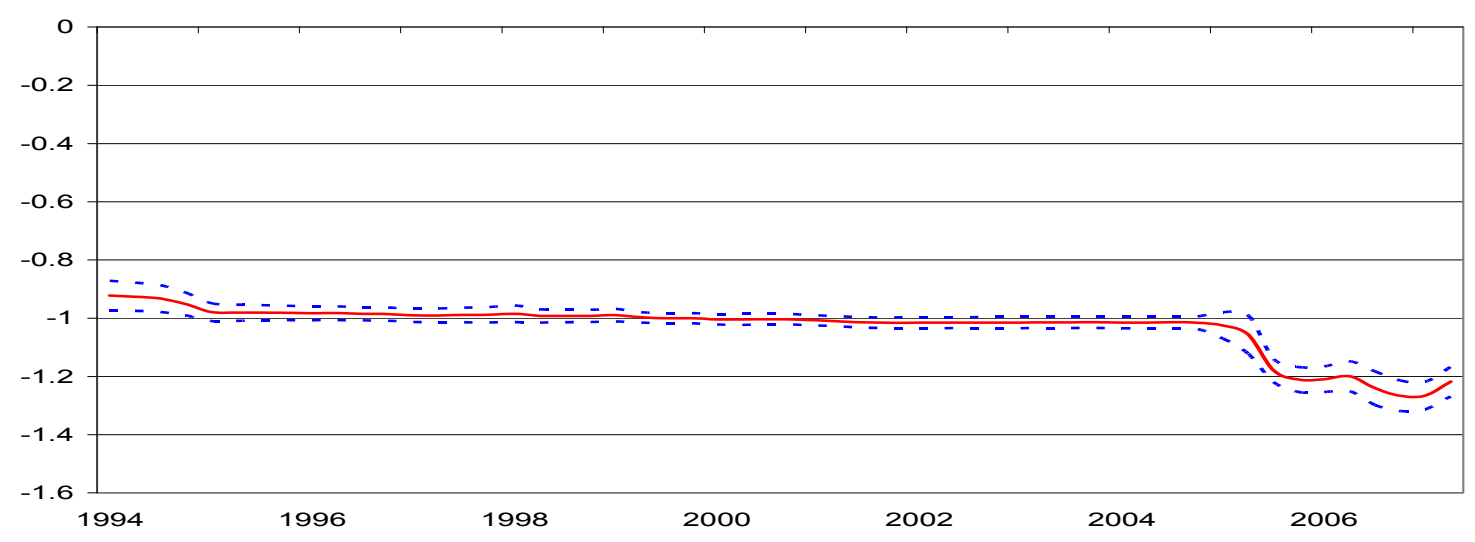

Note: Plots report coefficient estimates from regression of change in central bank domestic credit on change in foreign reserves (defined as 4 quarter changes relative to stock of reserve money lagged 4 quarters) and nominal GDP growth (with one standard error bands). Coefficient observations correspond to calendar date of $40^{\text {th }}$ quarter of rolling sample period. 
Figure 4. Coefficient of Variation of Sterilization Coefficients

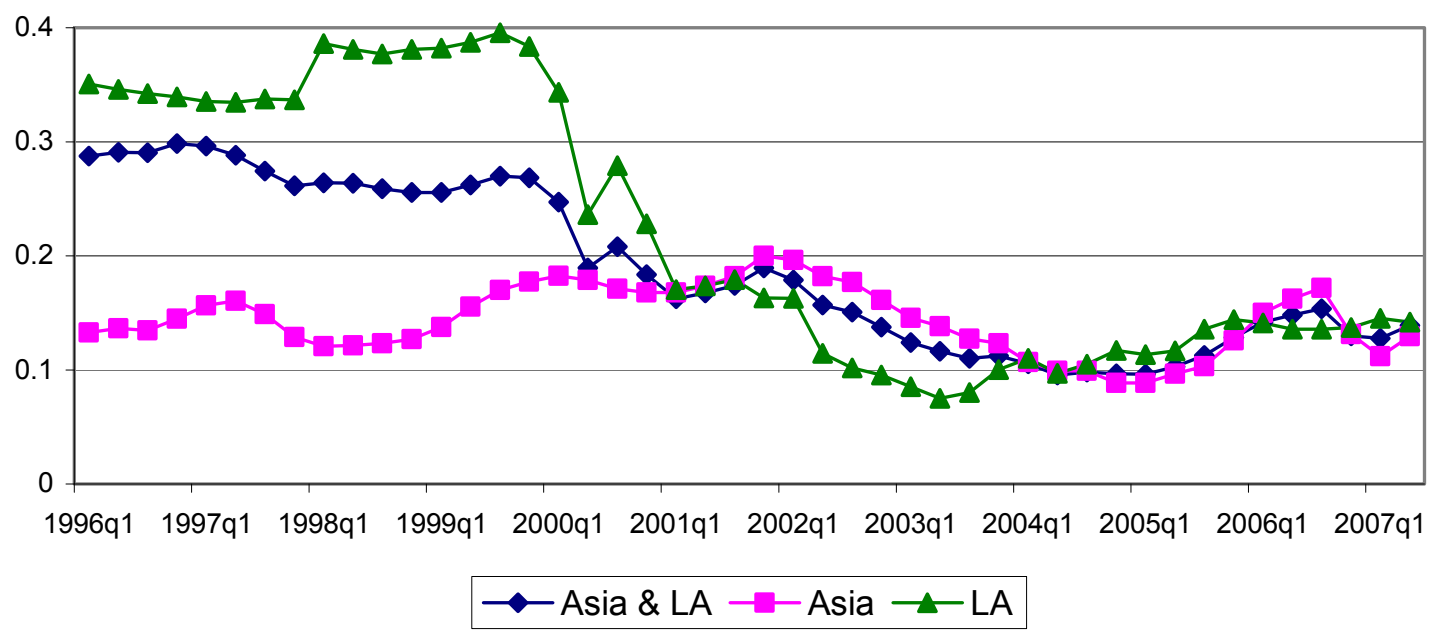

Note: Calculations based on coefficient estimates from regression of central bank net domestic credit on foreign reserve change and nominal GDP growth for countries in Asia (China, Indonesia, Korea, Malaysia, Pakistan, the Philippines, Singapore, Thailand) and Latin America (Argentina, Brazil, Chile, Colombia, Mexico, Peru). Coefficient observations correspond to calendar date of $40^{\text {th }}$ quarter of rolling sample period. 
Figure 5a. China Central Bank and and U.S. Treasury 1-Year Interest Rates (in percent)

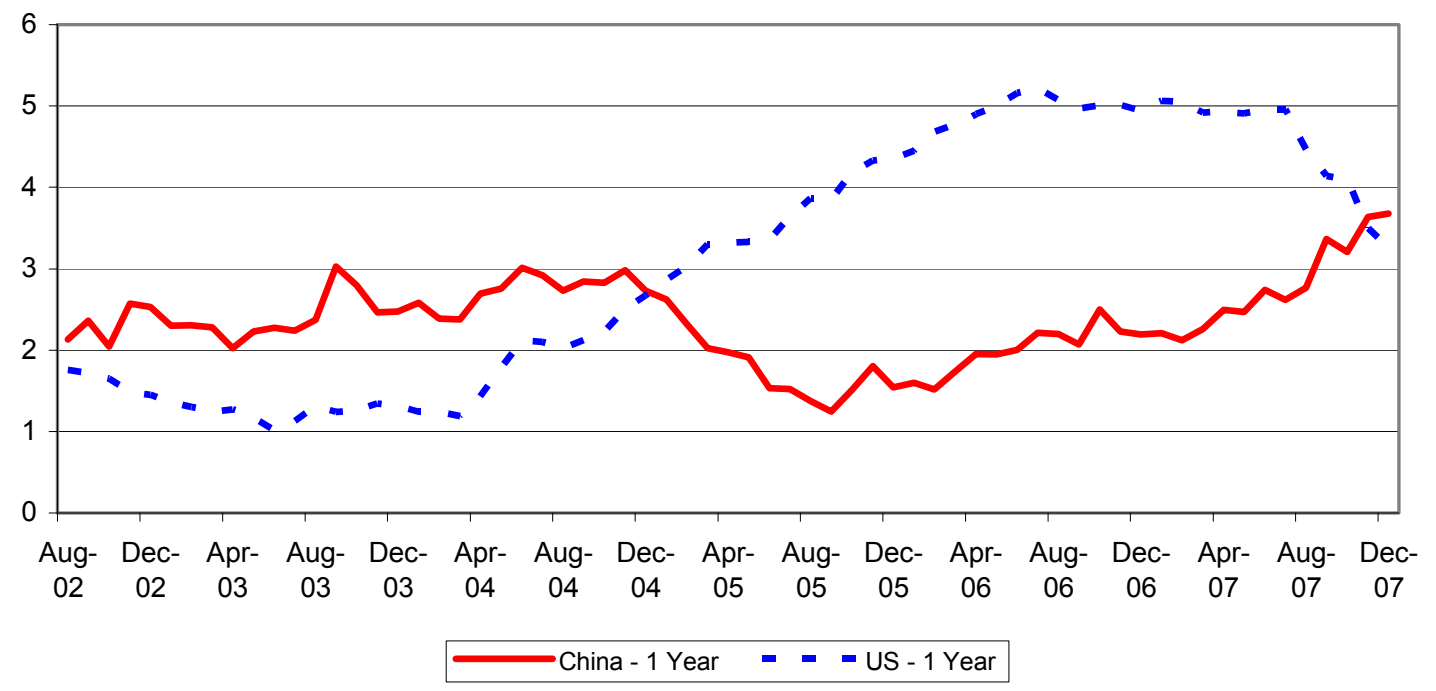

Figure 5b. Asian Bond Spreads over U.S. Treasury 1-Year Interest Rates (in percent)

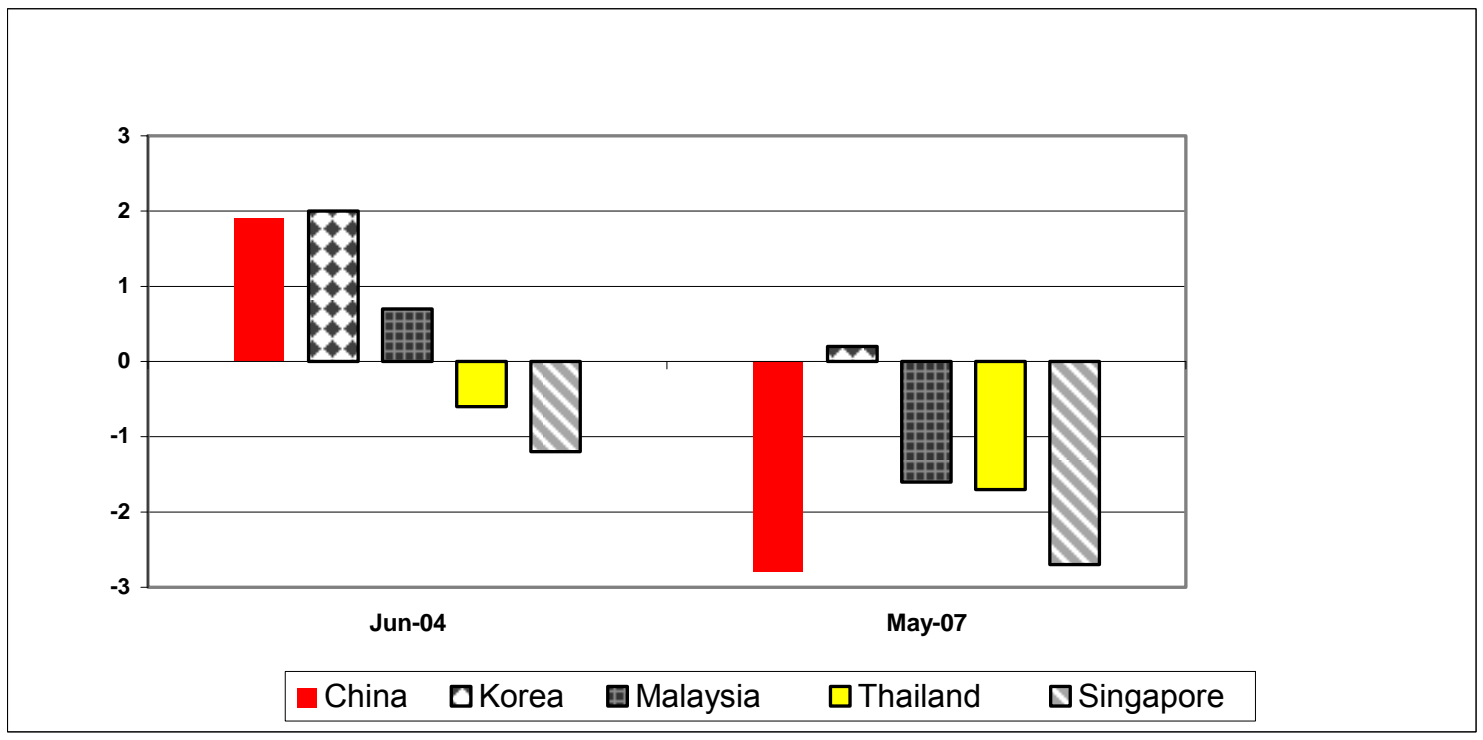




\section{Appendix Figures. Sterilization Coefficients from Alternative Rolling Regressions}

Panel A: Selected Asian Countries

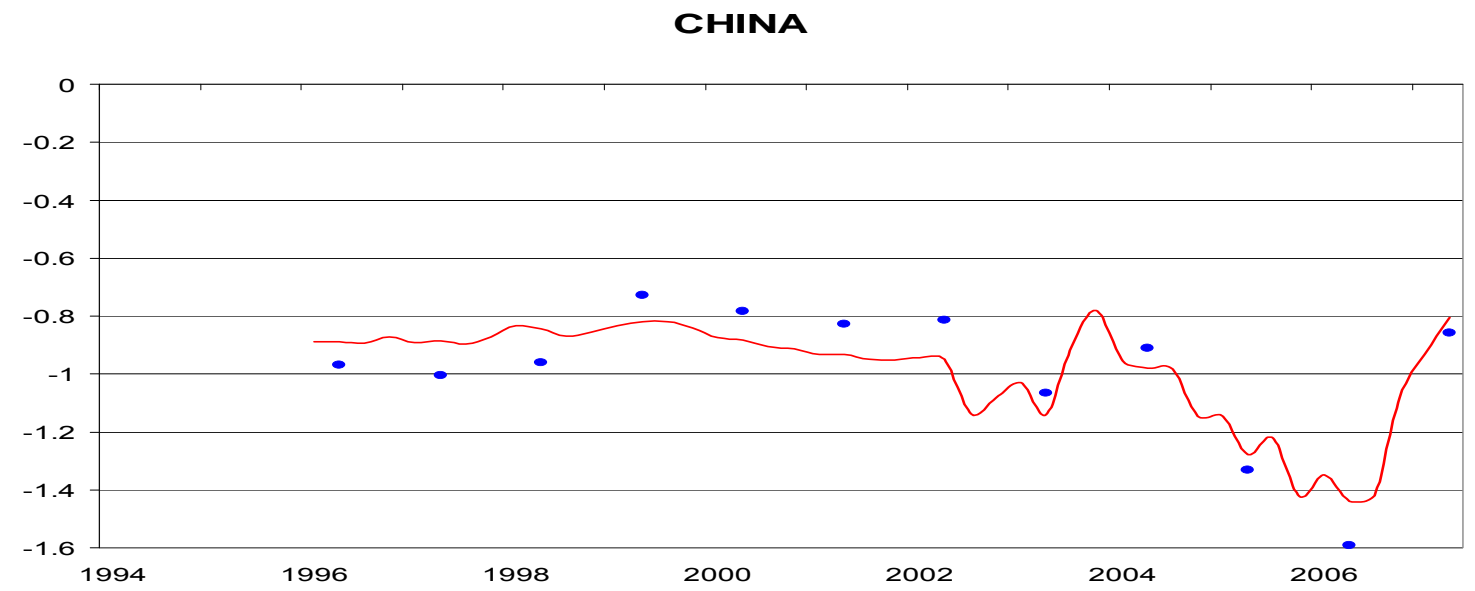

KOREA

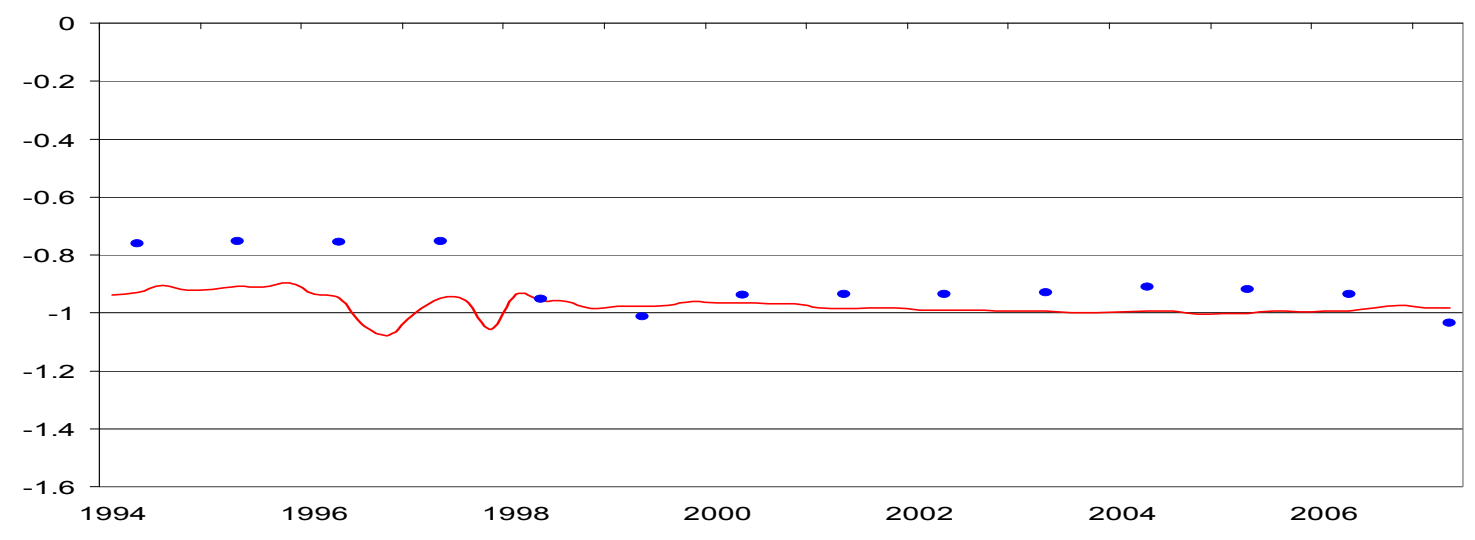

THAILAND

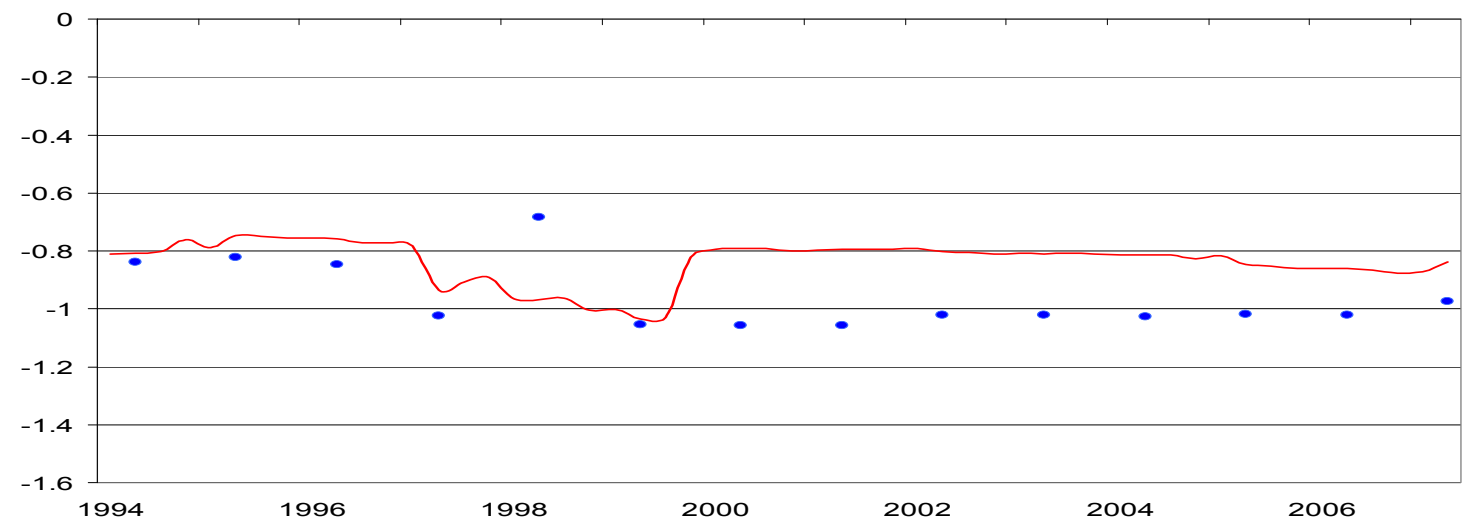


Appendix Figures. Sterilization Coefficients from Alternative Rolling Regressions

\section{Panel B: Other Selected Asian Countries}

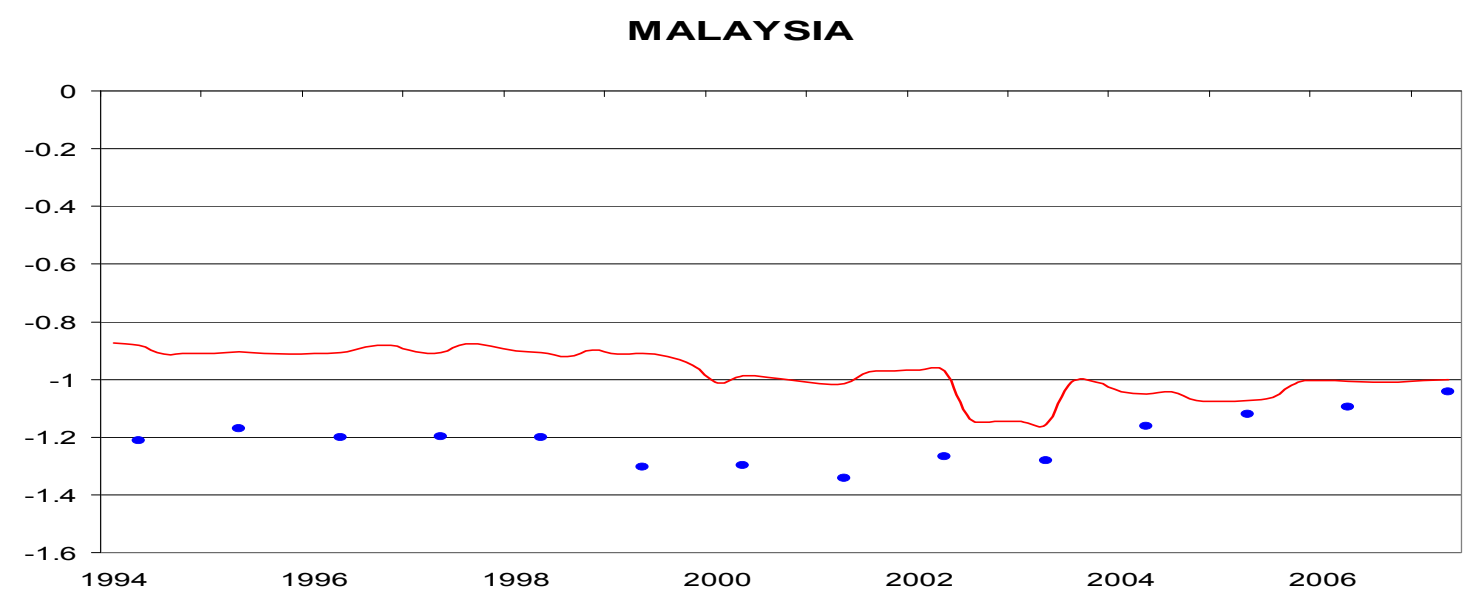

SINGAPORE
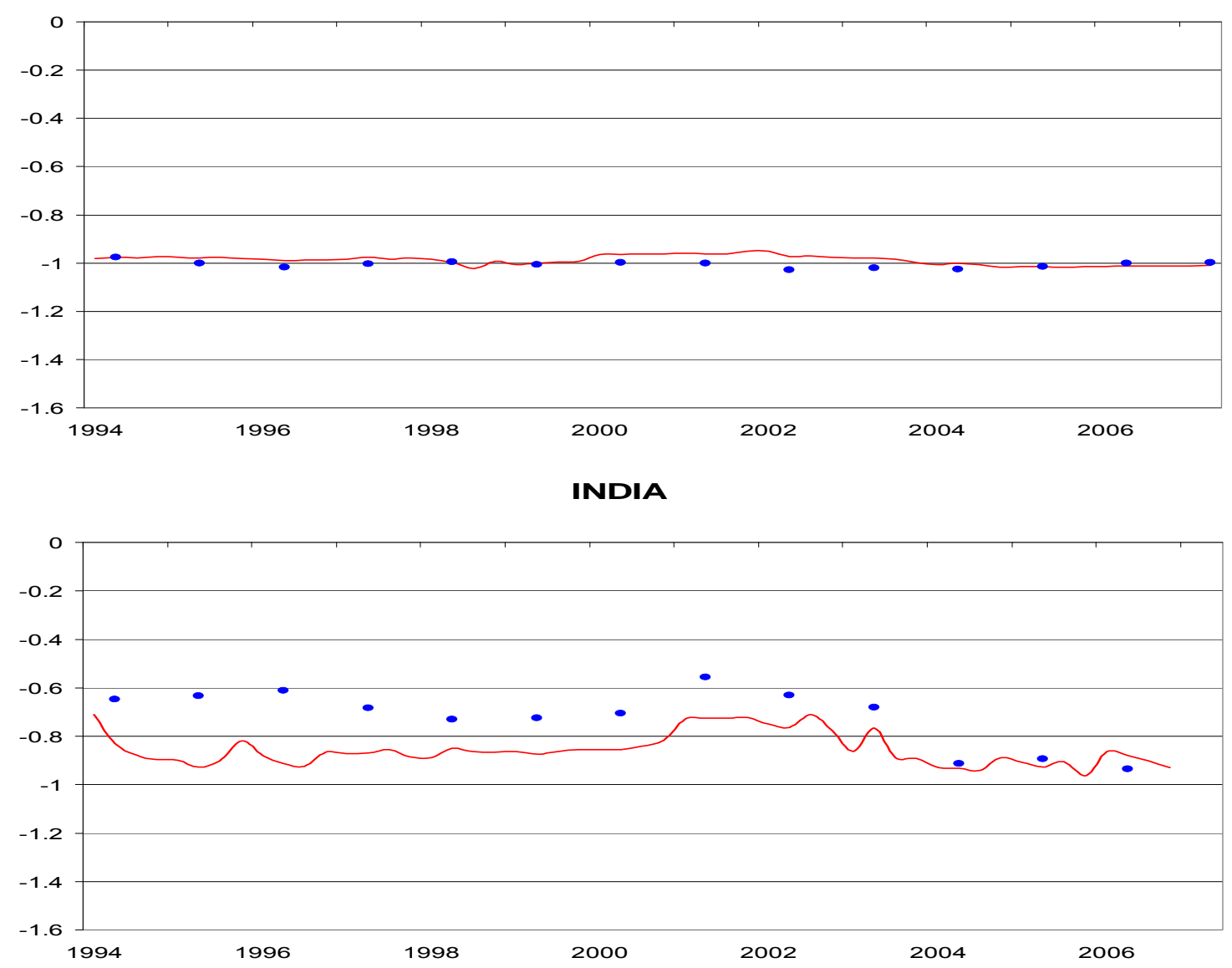


\section{Appendix Figures. Sterilization Coefficients from Alternative Rolling Regressions}

\section{Panel C. Selected Latin American Countries \\ ARGENTINA}

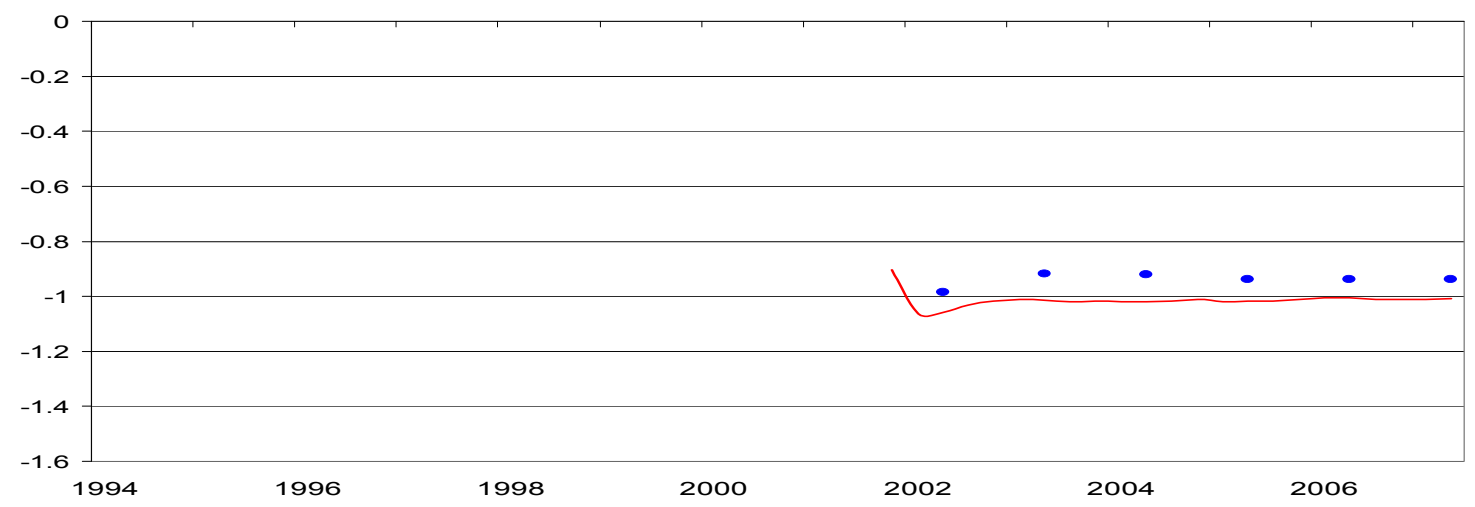

BRAZIL

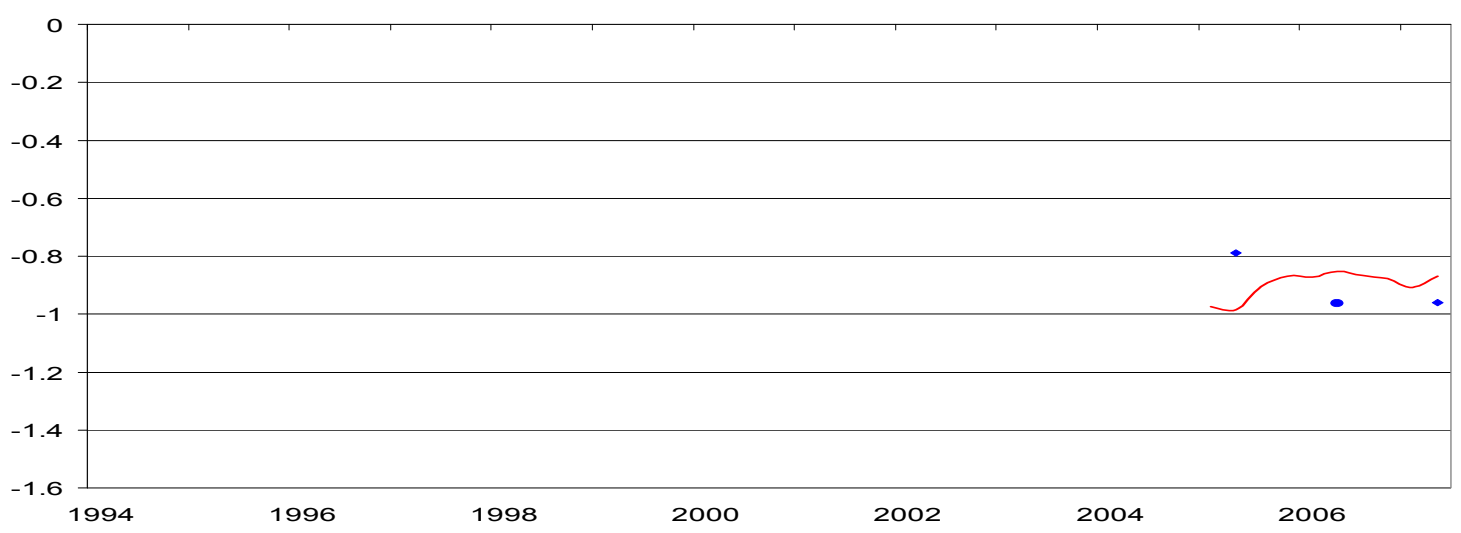

MEXICO

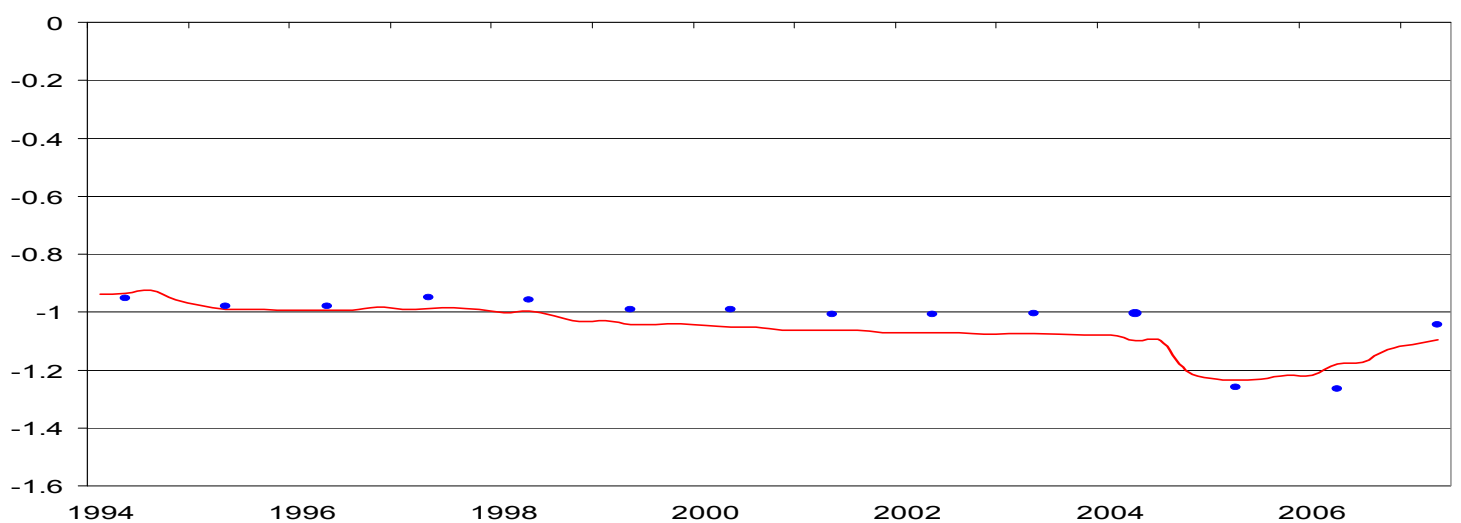

Note: Coefficient estimates from regression of the change in central bank domestic credit assets on the change in net foreign reserves (scaled by lagged reserve money) and nominal GDP growth. Solid line corresponds to regressions using (nonoverlapping) quarterly observations of 1 quarter changes with lagged dependent variable and quarterly dummies as explanatory variables. Dots correspond to regressions using (nonoverlapping) yearly observations of 4 quarter changes (from Q2 of each year). Coefficient observations correspond to calendar date of $40^{\text {th }}$ quarter or $10^{\text {th }}$ year of rolling sample period. 


\section{Model Appendix}

This Appendix analyzes the costs of sterilization by formulating a model of the determinants of the substitutability between domestic and foreign bonds as characterized by the marginal increase in the interest rate differential associated with reducing the share of foreign bonds in private portfolios.

We consider a country where agents face financial repression and uncertainty about domestic price inflation, currency depreciation, and tax rate on returns. The real yield to domestic residents to holding domestic and foreign bonds $\left(B, B^{*}\right)$ are

$$
\begin{aligned}
& r=i-\pi, \\
& r^{*}=i^{*}+e-t^{*}-\pi,
\end{aligned}
$$

where $i, i^{*}$ denote nominal interest returns, $\pi$ is the domestic inflation rate, $e$ is the depreciation rate of domestic currency, and $t^{*}$ is the tax on returns to holding foreign assets, reflecting the realized costs of financial repression; $\pi, e$, and $t^{*}$ are all stochastic. The tax rate $t^{*}$ reflects the de-facto degree of financial repression, which may include regulations inhibiting or penalizing the holding of foreign assets.

We assume agents are risk averse, with mean variance preferences:

$$
U=U\left[E[W], \sigma_{W}^{2}\right] ; \quad W=s(1+r)+(1-s) W\left(1+r^{*}\right) .
$$

The expected real yield differential can be solved as

$$
E\left[r^{*}\right]-E[r]=\theta \sigma_{r-r^{*}}^{2}\left(\frac{B^{*}}{W}-\gamma\right)
$$

where $\quad \gamma=\frac{\sigma_{r}^{2}-2 \rho_{r, r^{*}} \sigma_{r} \sigma_{r^{*}}}{\sigma_{r-r^{*}}^{2}} ; \quad \theta=-\frac{U_{2} W}{U_{1}} ; \quad \sigma_{r-r^{*}}^{2}=\sigma_{r}^{2}+\sigma_{r^{*}}^{2}-2 \rho_{r, r^{*}} \sigma_{r} \sigma_{r^{*}}$.

Hence, sterilized intervention that reduces the share of foreign assets in the private portfolio, $B^{*} / W$, increases the expected interest rate differential, $E[r]-E\left[r^{*}\right]$, by the degree of risk aversion times the variance of the real interest rate differential, $\theta \sigma_{r-r^{*}}^{2}$.

The variables $\pi, e$, and $t^{*}$ are all stochastic. Specifically, we denote by $a_{k}^{\prime}, \varepsilon_{k}$ the constant and the shock associated with variables $k, \quad k=\pi, e, t^{*}$ as

$$
\pi=a_{\pi}^{\prime}+\varepsilon_{\pi} ; \quad e=a_{e}^{\prime}+\varepsilon_{e} ; \quad t^{*}=a_{t^{*}}^{\prime}+\varepsilon_{t} .
$$

We further assume (i) expected domestic inflation and the depreciation rate are correlated, (ii) shocks are zero mean and may be correlated and (iii) there are two types of agents $(i=l, h)$, with differential costs of holding foreign assets potentially different degree of risk aversion, with the “favored" type $i=l$ having a low $t^{*}$, implying 


$$
\pi=a_{\pi} e+\varepsilon_{\pi} ; \quad e=a_{e}+\varepsilon_{e} ; \quad t^{*}=c_{i}\left(a_{t^{*}}+\varepsilon_{t^{*}}\right), i=l, h, c_{h}>c_{l}
$$

where $E\left[\varepsilon_{\pi}\right]=E\left[\varepsilon_{e}\right]=E\left[\varepsilon_{t^{*}}\right]=0$.

Noting that $r-r^{*}=i-i^{*}+t^{*}-e$, it follows that

$$
\sigma_{r-r^{*}}^{2}=\sigma_{t^{*}}^{2}+\sigma_{e}^{2}-2 \rho_{t^{*}, e} \sigma_{t^{*}} \sigma_{e}=\left(c_{i}\right)^{2} \sigma_{\varepsilon_{t^{*}}}^{2}-2 c_{i} \rho_{\varepsilon_{t^{*}}, \varepsilon_{e}} \sigma_{\varepsilon_{t^{*}}} \sigma_{\varepsilon_{e}}+\sigma_{\varepsilon_{e}}^{2} .
$$

Consequently,

$$
\frac{d \sigma_{r-r^{*}}^{2}}{d c_{i}}=2 c_{i}\left(\sigma_{\varepsilon_{t^{*}}}^{2}-\rho_{\varepsilon_{t^{*}}, \varepsilon_{e}} \sigma_{\varepsilon_{t^{*}}} \sigma_{\varepsilon_{e}}\right)
$$

We presume that the correlation between depreciation and the financial repression tax is positive, i.e. $\rho_{\varepsilon_{t^{*}}, \varepsilon_{e}}>0$ (see Giovannini and De Melo, 1993).

Expression (A6) implies that a higher correlation between the exchange rate depreciation rate and financial repression tax reduces the cost of sterilization. This effect is larger the greater is the extent of financial repression (i.e., the higher is $c$, and the greater is the share of agents facing higher $c$ ). In the limiting case when the correlation approaches 1 , it follows that $\varepsilon_{t^{*}} \cong k \varepsilon_{e}$, where $k$ is a constant, and

$$
\sigma_{r-r^{*}}^{2} \underset{\rho_{t^{*}, e} \rightarrow 1}{\longrightarrow}\left(1-c_{i} k\right)^{2} \sigma_{\varepsilon_{e}}^{2} .
$$

Consequently, the ability to sterilize depends on imperfect substitutability of assets in a world where the costs of trading assets varies systematically across agents (due to possible scale effects) and across asset classes (due to varying liquidity and risk characteristics). Policies fostering greater domestic financial repression also reduce the costs of sterilization. This suggests that countries able and willing to engage in greater financial sterilization will be able to sustain the policy configuration of reserve hoarding and sterilizing for a longer period of time. 